\title{
Photoinduced electron transfer in linear triarylamine- photosensitizer-anthraquinone triads with ruthenium(II), osmium(II), and iridium(III)
}

\begin{tabular}{|r|l|}
\hline Journal: & Inorganic Chemistry \\
\hline Manuscript ID: & ic-2012-00558s.R1 \\
\hline Manuscript Type: & Article \\
\hline Date Submitted by the Author: & 27-Apr-2012 \\
\hline Complete List of Authors: & $\begin{array}{l}\text { Hankache, Jihane; University of Goettingen, Institute of Inorganic } \\
\text { Chemistry } \\
\text { Niemi, Marja; Tampere University of Technology, Department of Chemistry } \\
\text { and Bioengineering } \\
\text { Lemmetyinen, Helge; Tampere University of Technology, Department of } \\
\text { Chemistry and Bioengineering } \\
\text { Wenger, Oliver; University of Goettingen, Institute of Inorganic Chemistry }\end{array}$ \\
\hline
\end{tabular}

SCHOLARONE ${ }^{\text {M }}$

Manuscripts 


\title{
Photoinduced electron transfer in linear triarylamine-
}

\section{photosensitizer-anthraquinone triads with ruthenium(II), osmium(II), and iridium(III)}

\author{
Jihane Hankache ${ }^{\dagger}$ Marja Niemi, ${ }^{\ddagger}$ Helge Lemmetyinen, ${ }^{*}, \underset{\text { and Oliver S. Wenger }}{ }{ }^{*} \dagger$ \\ ${ }^{\dagger}$ Georg-August-Universität Göttingen, Institut für Anorganische Chemie, Tammannstrasse 4, D-37077 \\ Göttingen, Germany \\ ${ }^{\ddagger}$ Tampere University of Technology, Department of Chemistry and Bioengineering, P. O. Box 541, FIN- \\ 33101 Tampere, Finland \\ helge.lemmetyinen@tut.fi, oliver.wenger@chemie.uni-goettingen.de
}

RECEIVED DATE (to be automatically inserted after your manuscript is accepted if required according to the journal that you are submitting your paper to)

\begin{abstract}
A rigid rod-like organic molecular ensemble comprised of a triarylamine electron donor, a 2,2'bipyridine (bpy) ligand, and a 9,10-anthraquinone acceptor was synthesized and reacted with suitable metal precursors to yield triads with $\mathrm{Ru}(\mathrm{bpy})_{3}{ }^{2+}, \mathrm{Os}(\mathrm{bpy})_{3}{ }^{2+}$, and $\left[\operatorname{Ir}(2-(p \text {-tolyl }) \text { pyridine })_{2}(\mathrm{bpy})\right]^{+}$ photosensitizers. Photoexcitation of these triads leads to long-lived charge-separated states $(\tau=80 \mathrm{~ns}-$ $1300 \mathrm{~ns}$ ) containing a triarylamine cation and an anthraquinone anion, as observed by transient
\end{abstract}


absorption spectroscopy. From a combined electrochemical and optical spectroscopic study the thermodynamics and kinetics for the individual photoinduced charge-separation and thermal chargerecombination events were determined; in some cases measurements on suitable donor-sensitizer or sensitizer-acceptor dyads were necessary. In the case of the ruthenium and iridium triads, the fully charge-separated state is formed in nearly quantitative yield.

\section{INTRODUCTION}

The construction of molecular triads with linear alignment of an electron donor, photosensitizer, and an electron acceptor is of long-standing interest. ${ }^{1}$ A key advantage of linear rigid rod-like constructs is a maximum separation distance of the electron-hole pair in the charge-separated state. The traditional approach to obtaining linear triads for vectorial electron transfer with $\mathrm{d}^{6}$ metal photosensitizers involves the use of $2,2^{\prime} ; 6^{\prime}, 2^{\prime \prime}$-terpyridine (tpy) ligands, which are substituted at the $4^{\prime}$-position of the central pyridine ring with appropriate electron donors or acceptors (Scheme $1 \mathrm{a}) .^{2-10}$

Scheme 1. Possible constructs of molecular triads incorporating $d^{6}$ metal complexes (here: $\mathrm{Ru}(\mathrm{II})$ ) as photosensitizers between electron donors (D) and electron acceptors (A).

(a)

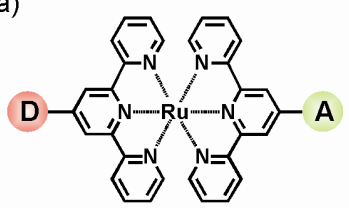

(c)

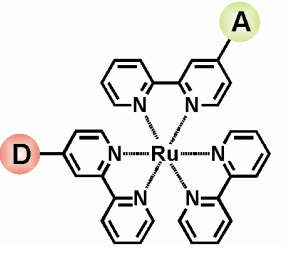

(b)

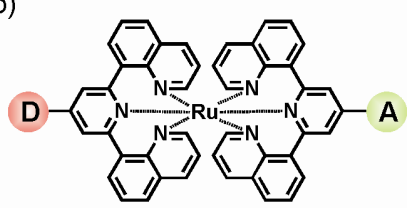

(d)

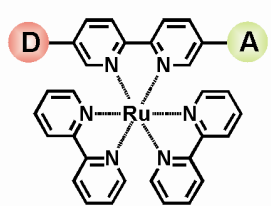


However, the $\mathrm{Ru}(\mathrm{tpy}){ }_{2}{ }^{2+}$ photosensitizer has rather poor photophysical properties when compared to $\mathrm{Ru}(\mathrm{bpy}){ }_{3}{ }^{2+}$ (bpy $=2,2^{\prime}$-bipyridine), particularly its short ${ }^{3} \mathrm{MLCT}$ (metal-to-ligand charge transfer) lifetime is less than optimal for photoinduced electron transfer chemistry. ${ }^{11}$ Despite the need for shorter excitation wavelengths, isoelectronic $\operatorname{Ir}(\operatorname{tpy})_{2}{ }^{3+}$ complexes represent an attractive alternative from a photophysical point of view, but they are not at all easy to synthesize. ${ }^{8,12-13}$ An interesting, newly discovered alternative option are bis(diquinolinyl)pyridine ligands, which are structurally similar to tpy (Scheme 1b) but ligate to ruthenium(II) with a significantly larger bite angle, which in turn results in more favorable photophysical properties of the complex. ${ }^{14-17}$ Numerous molecular electron transfer triads based on the $\mathrm{Ru}(\mathrm{bpy}){ }_{3}{ }^{2+}$ photosensitizer have been explored, but when substituting one bpy ligand with an electron donor while equipping a second bpy ligand with an electron acceptor (Scheme 1c), one is often confronted with the problem of isomerism, and analysis of the electron transfer kinetics may become tricky. ${ }^{18-28}$ Moreover, the resulting molecular constructs are not linear. A viable solution to this problem is to attach the donor and the acceptor at the 5- and 5'-positions of a given bpy ligand (Scheme 1d). We recently communicated preliminary results on what we believe to be the first rigid rod-like (linear) triad based on the Ru(bpy) ${ }_{3}^{2+}$ photosensitizer. ${ }^{29}$ Here, we present a more detailed study including transient absorption data at higher temporal resolution, and an extension of the work to analogous triads with $\mathrm{Os}(\mathrm{bpy})_{3}{ }^{2+}$ and a cyclometalated iridium(III) complex as photosensitizing units. Specifically, we synthesized and investigated the three triads from Scheme 2 along with a series of suitable molecular dyads. The triads are comprised of a triarylamine (TAA) electron donor, a $\mathrm{d}^{6}$ metal diimine photosensitizer $\left(\mathrm{Ru}^{\mathrm{II}}, \mathrm{Os}^{\mathrm{II}}, \mathrm{Ir}^{\mathrm{III}}\right)$, and a 9,10-anthraquinone (AQ) unit, which is acting as a terminal electron acceptor. The dyads contain either only the donor and the sensitizer, or the sensitizer and the acceptor. 
Scheme 2. The molecules investigated in this work. TAA = triarylamine; $A Q=$ anthraquinone.

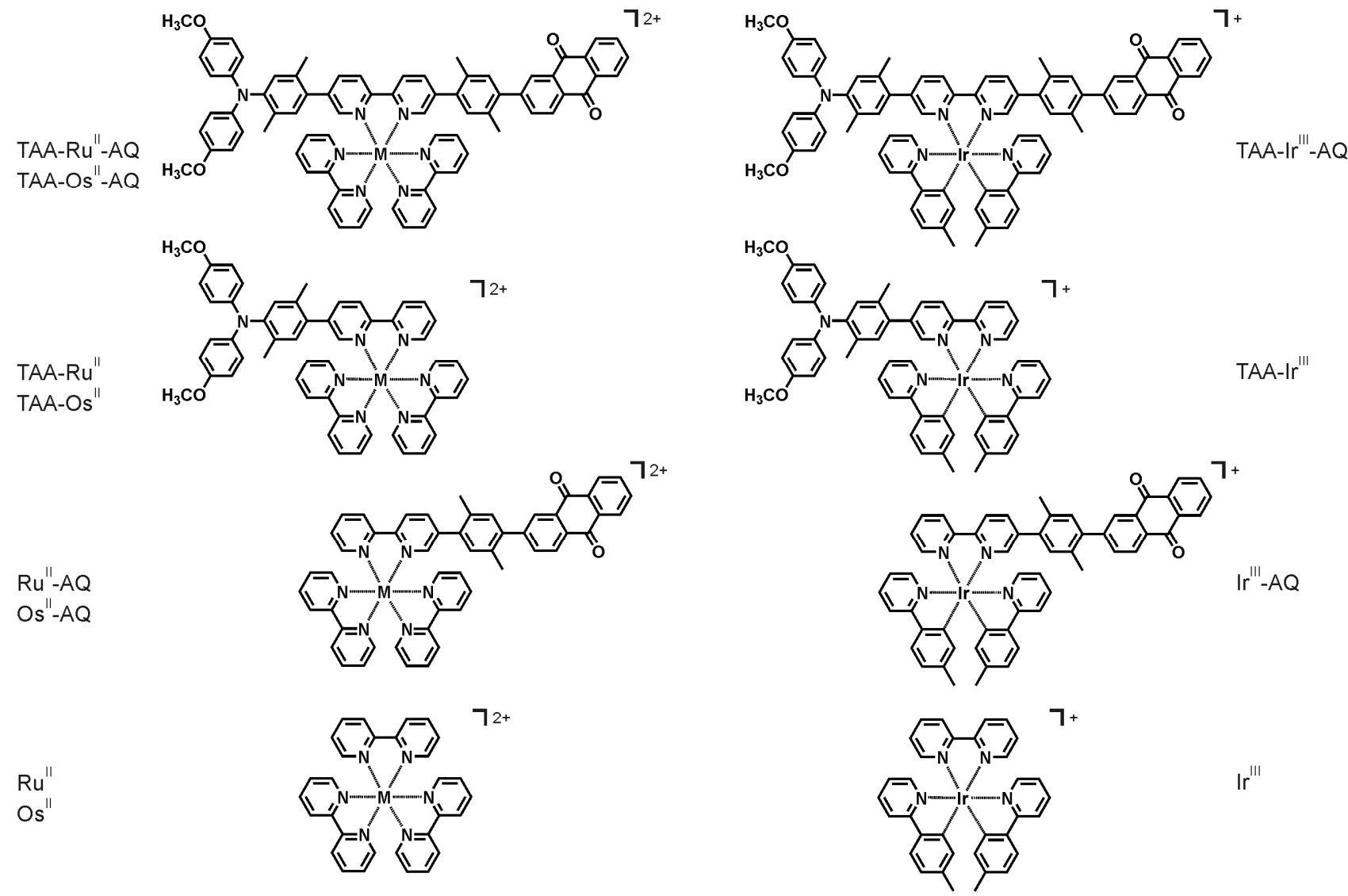

\section{RESULTS AND DISCUSSION}

Synthesis. The synthesis of the rigid rod-like triarylamine-2,2'-bipyridine-anthraquinone unit was described in detail in our prior communication. ${ }^{29}$ Briefly, the synthetic strategy is based on $5,5^{\prime}-$ dibromo-2,2'-bipyridine as a starting material to which 4-(trimethylsilyl)phenylboronic acid was attached on both sides in a Suzuki cross-coupling reaction. After trimethylsilyl-halogen exchange the resulting molecule can be coupled to anthraquinone-2-boronic acid pinacol ester in a Suzuki-type crosscoupling reaction. A subsequent palladium(0)-catalyzed N-C coupling reaction with 4,4'dimethoxydiphenylamine then yields the desired molecular rod in $33 \%$ overall yield. The syntheses of the dyads departed from 5-bromo-2,2`-bipyridine and relied on the same coupling strategy involving 4- 
(trimethylsilyl)phenylboronic acid as a first coupling partner, trimethylsilyl-halogen exchange, followed by reaction either with anthraquinone-2-boronic acid pinacol ester or 4,4'-dimethoxydiphenylamine. Detailed synthetic protocols can be found in the Supporting Information of our prior communication. ${ }^{29}$ Complexation of the dyad and triad ligands to $\mathrm{Ru}(\mathrm{bpy})_{2} \mathrm{Cl}_{2}, \quad \mathrm{Os}(\mathrm{bpy})_{2} \mathrm{Cl}_{2}$, and $[\operatorname{Ir}(2-(p-$ tolyl)pyridine $\left.)_{2} \mathrm{Cl}\right]_{2}{ }^{30-31}$ occurred following standard protocols. ${ }^{32}$ Product characterization data are given in the Experimental Section.

Optical absorption and luminescence spectroscopy. Figure 1 shows optical absorption spectra of the individual compounds from Scheme 2 in acetonitrile solution at room-temperature. The ruthenium complexes from panel (a) exhibit metal-to-ligand charge transfer (MLCT) absorption bands centered around $450 \mathrm{~nm}$ and a bpy-localized $\pi-\pi^{*}$ absorption band at $290 \mathrm{~nm}$. The AQ unit has relatively lowlying absorptions, which account for some of the additional extinction observable between 310 and 380 $\mathrm{nm}$ in the TAA-Ru ${ }^{\mathrm{II}}-\mathrm{AQ}$ and $\mathrm{Ru} \mathrm{u}^{\mathrm{II}}-\mathrm{AQ}$ compounds.

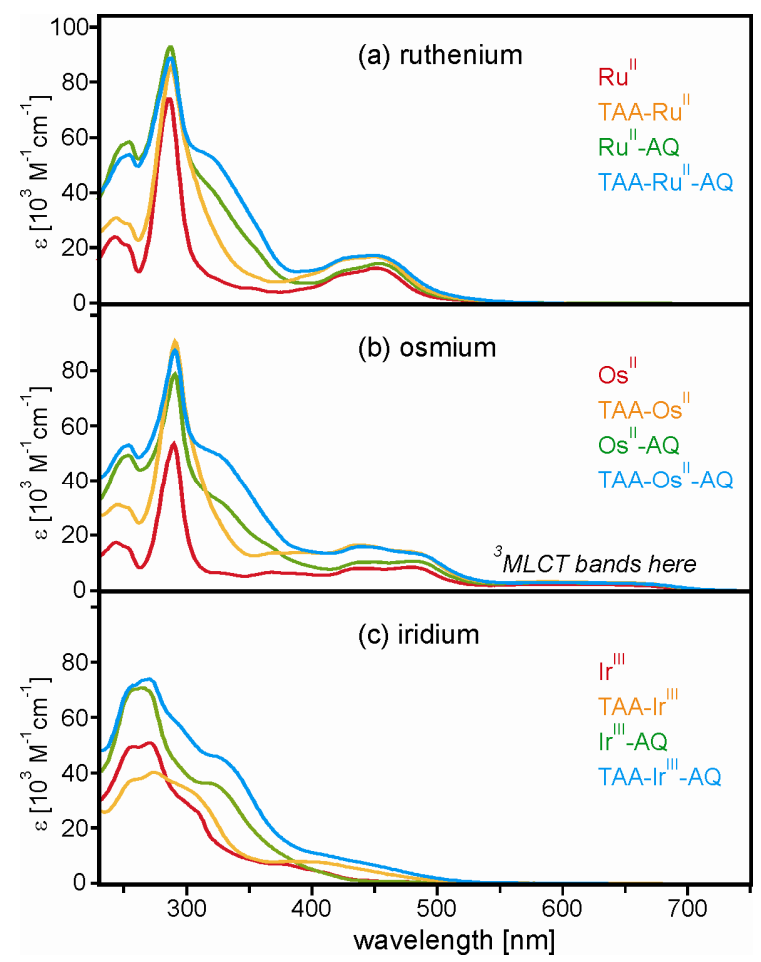

Figure 1. Optical absorption spectra of the 12 molecules from Scheme 2 in $\mathrm{CH}_{3} \mathrm{CN}$ at $25^{\circ} \mathrm{C}$. 
However, although the $p$-xylene spacer leads to significantly less $\pi$-conjugated systems than unsubstituted $p$-phenylene bridges, ${ }^{33-34}$ some of the extinction in the $310-380 \mathrm{~nm}$ spectral range is likely to be caused by the molecular bridge and/or an increase of $\pi$-conjugation in the overall system. The TAA unit absorbs predominantly at shorter wavelengths and contributes substantially to the extinction below $300 \mathrm{~nm}^{35-36}$

Expectedly, the osmium complexes from panel (b) exhibit the same spectral features as the isoelectronic ruthenium compounds, only that the ${ }^{1}$ MLCT bands are red-shifted and that the ${ }^{3}$ MLCT absorptions between 520 and $700 \mathrm{~nm}$ now become easily detectable as a consequence of the relaxation of spin selection rule. As in the case of ruthenium, the AQ unit causes the TAA-Os ${ }^{\mathrm{II}}-\mathrm{AQ}$ and $\mathrm{Os}^{\mathrm{II}}-\mathrm{AQ}$ molecules to absorb more strongly between 310 and $380 \mathrm{~nm}$ than the TAA-Os ${ }^{\mathrm{II}}$ and Os ${ }^{\mathrm{II}}$ molecules.

The cyclometalated iridium complexes in panel (c) exhibit ${ }^{1}$ MLCT and ${ }^{3}$ MLCT absorptions in the 400-500 $\mathrm{nm}$ spectral range, and to the higher energy side these absorptions merge directly into intraligand $\pi-\pi^{*}$ absorptions. Thus, it is difficult to perform a clear distinction between absorptions that involve the metal center and absorptions which do not. Be that as it may, the global appearance of all absorption spectra in Figure 1 is that expected for $\mathrm{d}^{6}$ metal complexes of this type. ${ }^{11,37-42}$ The dyad and triad spectra of the ruthenium and osmium triads correspond more or less (but not precisely) to the sum of the absorption spectra of the individual molecular components, indicating that the overall systems are electronically weakly coupled. At donor-photosensitizer and photosensitizer-acceptor distances of roughly $4.3 \AA$ (i. e., the length of one $p$-xylene spacer) this is to be expected. However, for the TAA-Ir dyad and the TAA-Ir-AQ triad the absorption spectra in Figure 1c reveal more pronounced interaction between the individual molecular moieties: There is a broad absorption band around $450 \mathrm{~nm}$, in a spectral region where none of the individual components absorbs. Similar observations have been made previously in a TAA-Ir(tpy) ${ }_{2}{ }^{3+}$ dyad. $^{43}$ 
Steady-state luminescence spectroscopy. All of the compounds from Scheme 2 are emissive when irradiating $\sim 10^{-5} \mathrm{M}$ (aerated) acetonitrile solutions of them with blue or UV light, albeit with widely varying luminescence intensities. Figure $2 \mathrm{a}$ shows the emission spectra of the four ruthenium compounds as detected after excitation at $450 \mathrm{~nm}$. The luminescence intensity of the $\mathrm{Ru}^{\text {II }}$ reference complex has been normalized artificially to a value of 1.0, all other luminescence intensities are scaled relative to this reference point. ${ }^{44}$ The $\mathrm{Ru}^{\mathrm{II}}-\mathrm{AQ}$ dyad exhibits an emission intensity practically on par with that of the ruthenium reference complex, while the TAA- $\mathrm{u}^{\mathrm{II}}$ and TAA-Ru ${ }^{\mathrm{II}}-\mathrm{AQ}$ molecules emit an order of magnitude weaker. Both the AQ and TAA units have energetically high lying triplet excited states $(\sim 2.7 \mathrm{eV}$ for $\mathrm{AQ}, \sim 3.2 \mathrm{eV}$ for TAA $),{ }^{45-46}$ hence excited-state deactivation by triplet-triplet energy transfer from the $\mathrm{Ru}(\mathrm{bpy})_{3}{ }^{2+}{ }^{3} \mathrm{MLCT}$ excited state at $2.12 \mathrm{eV}$ to either one of these two moieties is thermodynamically unlikely. ${ }^{47-50}$ Subsequent sections will demonstrate that electron transfer from the TAA unit to the ruthenium complex is in fact the predominant excited-state deactivation pathway in the TAA-Ru ${ }^{\text {II }}$ and TAA-Ru ${ }^{\text {II }}-A Q$ molecules.

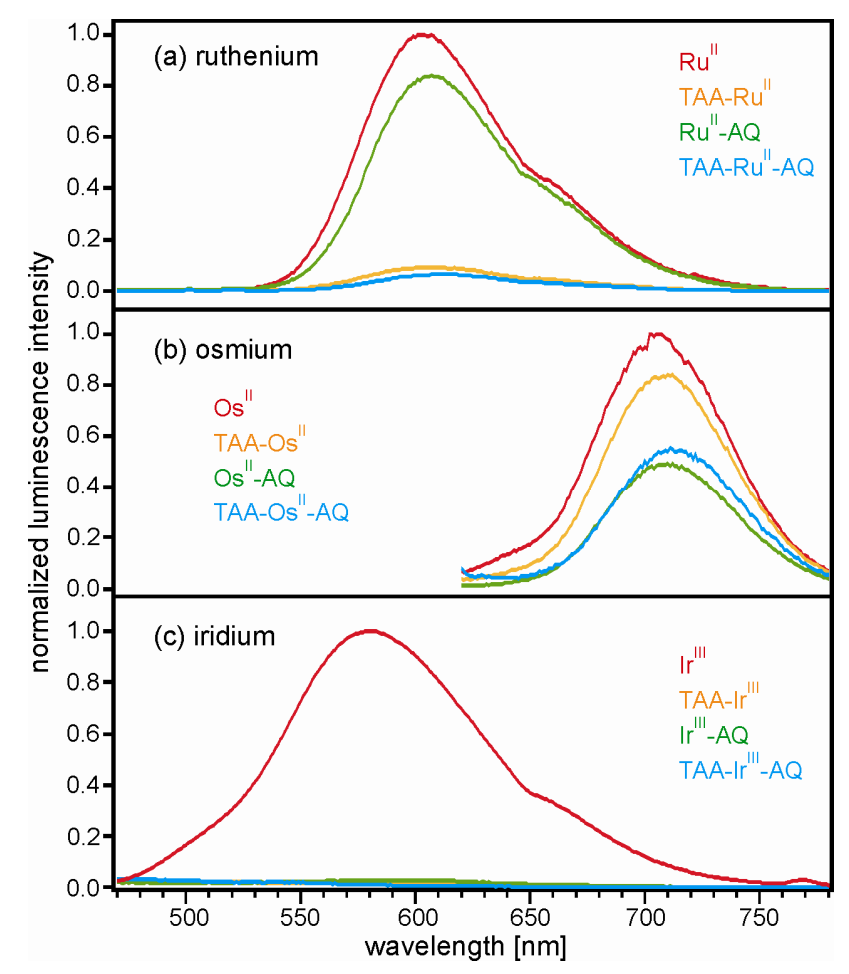


Figure 2. Luminescence spectra of the 12 molecules from Scheme 2 in aerated $\mathrm{CH}_{3} \mathrm{CN}$ at $25^{\circ} \mathrm{C}$. Excitation occurred at $450 \mathrm{~nm}$ in the case of the ruthenium and osmium molecules $(\mathrm{a}, \mathrm{b})$, and at $380 \mathrm{~nm}$ in the case of the iridium molecules (c). Relative emission intensities were corrected for differences in sample absorbance at the excitation wavelength, and the final intensities were normalized to a value of 1.0 for the reference complexes $\left(\mathrm{Ru}^{\mathrm{II}}, \mathrm{Os}^{\mathrm{II}}, \mathrm{Ir}^{\mathrm{III}}\right)$.

Expectedly, the ${ }^{3}$ MLCT emissions of the osmium compounds in Figure $2 \mathrm{~b}$ (excited at $450 \mathrm{~nm}$ ) are all significantly red-shifted with respect to the ruthenium complexes in Figure 2a. The emission intensities of the Os ${ }^{\mathrm{II}}$ reference complex and the TAA-Os ${ }^{\mathrm{II}}$ dyad are similar, while those of the Os ${ }^{\mathrm{II}}-\mathrm{AQ}$ dyad and the TAA-Os ${ }^{\mathrm{II}}-\mathrm{AQ}$ triad are nearly a factor of two less intense. Since the emissive ${ }^{3}$ MLCT state of the Os(bpy $)_{3}{ }^{2+}$ complex is at even lower energy $(1.79 \mathrm{eV})^{51}$ than that of $\mathrm{Ru}(\mathrm{bpy})_{3}{ }^{2+}$, triplet-triplet energy transfer is even less probable in this case. Indeed, the subsequent sections will demonstrate that electron transfer from photoexcited osmium to AQ is an important excited-state deactivation channel.

Figure 2c shows the luminescence spectra obtained from the iridium complexes after excitation at 380 nm. For cyclometalated iridium(III) complexes of this type, the emission is commonly of mixed ${ }^{3}$ MLCT / intraligand $\pi-\pi^{*}$ character. $^{40,42}$ Given the comparatively high energy of the emissive triplet states, the excited-state deactivation by triplet-triplet energy transfer is an energetically more viable option for the iridium dyads and triads than for the ruthenium and osmium compounds. Nevertheless, the subsequent paragraphs of this paper will show that the strong emission quenching observed in the TAA-Ir ${ }^{\mathrm{III}}$, Ir ${ }^{\mathrm{III}}$ AQ, and TAA-Ir ${ }^{\mathrm{III}}$-AQ molecules is predominantly the consequence of efficient excited-state deactivation by photoinduced electron transfer.

To summarize this paragraph on the steady-state luminescence properties we note that the ruthenium emission is quenched significantly in presence of the TAA donor while AQ has a weak influence, the osmium luminescence is quenched to a noticeable extent in presence of AQ while TAA has a weak influence, and the iridium luminescence is strongly susceptible to the presence of both TAA and AQ. 
Electrochemical investigations and energy level structure of the triads. Figure 3 shows the cyclic voltammograms of the compounds in Scheme 2 as measured in acetonitrile solution in presence of 0.1 $\mathrm{M}$ tetrabutylammonium hexafluorophosphate $\left(\mathrm{TBAPF}_{6}\right)$ as a supporting electrolyte. The reversible waves at $0.0 \mathrm{~V}$ vs. $\mathrm{Fc}^{+} / \mathrm{Fc}$ (dashed vertical lines) are due to ferrocene, which was added in small quantities to the solutions for internal voltage calibration. Vertical superposition of voltammograms from the reference complex (red traces), TAA-metal dyad (oranges traces), metal-AQ dyad (green traces), TAA-metal-AQ triad (blue traces) in each of the three panels (a, b, c) permits unambiguous assignment of the individual redox waves. The reduction potentials extracted from the ruthenium compounds in Figure 3 a are summarized in Table 1.

(a) ruthenium

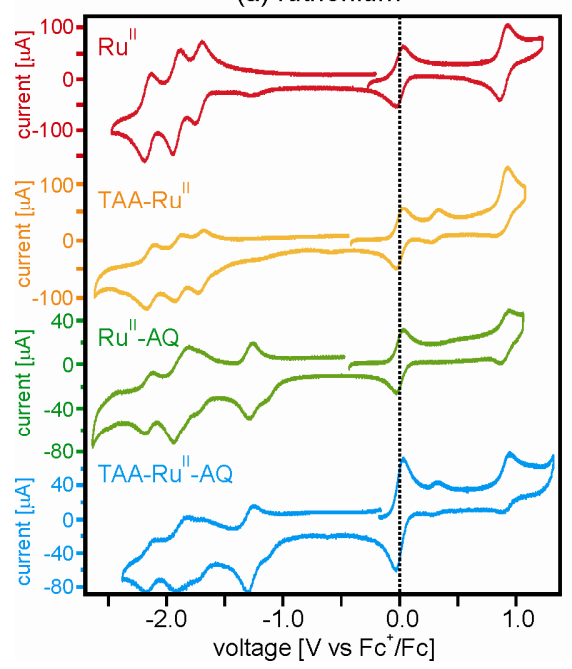

(b) osmium

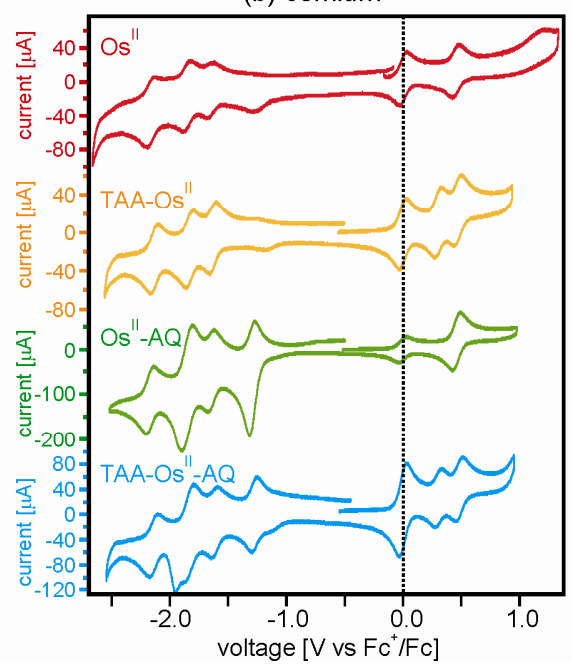

(c) iridium

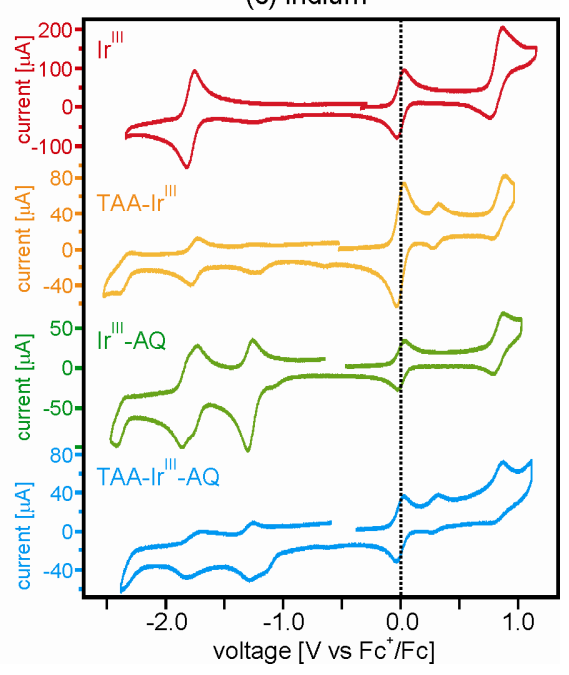

Figure 3. Cyclic voltammograms of the molecules from Scheme 2 in $\mathrm{CH}_{3} \mathrm{CN}$ in presence of $0.1 \mathrm{M}$ $\mathrm{TBAPF}_{6}$ as a supporting electrolyte. The waves at $0.0 \mathrm{~V}$ vs. $\mathrm{Fc}^{+} / \mathrm{Fc}$ (vertical dashed lines) are due to ferrocene which was added in small quantities for internal voltage calibration. 
Table 1. Reduction potentials for the individual redox-active components of the ruthenium molecules from Scheme 2. All values were extracted from the data in Figure $3 \mathrm{a}$ and are reported versus the ferrocenium/ferrocene $\left(\mathrm{Fc}^{+} / \mathrm{Fc}\right)$ couple in acetonitrile solution.

\begin{tabular}{|l|c|c|c|c|}
\hline & $\mathrm{Ru}(\mathrm{bpy})_{3}{ }^{2+}$ & $\mathrm{TAA}^{\mathrm{Ru}}{ }^{\mathrm{II}}$ & $\mathrm{Ru}{ }^{\mathrm{II}}-\mathrm{AQ}$ & $\mathrm{TAA}^{\mathrm{R}}{ }^{\mathrm{II}}-\mathrm{AQ}$ \\
\hline $\mathrm{Ru}(\mathrm{III} / \mathrm{II})$ & 0.89 & 0.89 & 0.90 & 0.92 \\
\hline $\mathrm{TAA}^{+/ 0}$ & & 0.30 & & 0.30 \\
\hline $\mathrm{AQ}^{0 /-}$ & & & -1.28 & -1.27 \\
\hline $\mathrm{bpy}^{0 /-}$ & -1.72 & -1.70 & -1.72 & -1.73 \\
\hline $\mathrm{bpy}^{0 /-}$ & -1.91 & -1.90 & -1.90 & -1.86 \\
\hline $\mathrm{bpy}^{0 /-}$ & -2.15 & -2.13 & -2.14 & -2.13 \\
\hline
\end{tabular}

bpy- and AQ-localized one-electron reductions as well as TAA- and metal-localized one-electron oxidations are found to exhibit peak-separations near the expected $59 \mathrm{mV}$, but the oxidation processes have higher peak currents in the oxidative than in the reductive sweep (ratios vary between 1:1 and $\sim 30: 1)$.

Oxidation of $\mathrm{Ru}(\mathrm{II})$ to $\mathrm{Ru}(\mathrm{III})$ occurs at a potential of $0.9 \mathrm{~V}$ vs. $\mathrm{Fc}^{+} / \mathrm{Fc}$, in line with prior investigations. ${ }^{38-39,52}$ Three bpy-localized reductions of the metal complex occur between -1.72 and $2.15 \mathrm{~V}$ vs. $\mathrm{Fc}^{+} / \mathrm{Fc}$, also in agreement with literature values. ${ }^{53-54}$ Although these are clearly ligandcentered reductions, for convenience we will later designate the first of these reduction processes as a reduction of the ruthenium(II) complex to a ruthenium(I) species $\left(\mathrm{Ru}^{\mathrm{II}} / \mathrm{Ru}^{\mathrm{I}}\right)$. Oxidation of the TAA unit occurs at $0.30 \mathrm{~V}$ vs. $\mathrm{Fc}^{+} / \mathrm{Fc}$, reduction of $\mathrm{AQ}$ is at $-1.27 \mathrm{~V}$ vs. $\mathrm{Fc}^{+} / \mathrm{Fc}$, both in agreement with previously reported redox potentials for these moieties. ${ }^{19,35-36,55-57}$ The fact that the redox potentials of all individual molecular components are nearly identical to those reported for their isolated counterparts is another indication that the molecular dyads and triads from Scheme 2 are electronically weakly coupled systems. 
Table 2. Reduction potentials for the individual redox-active components of the osmium molecules from Scheme 2. All values were extracted from the data in Figure $3 b$ and are reported versus the ferrocenium/ferrocene $\left(\mathrm{Fc}^{+} / \mathrm{Fc}\right)$ couple in acetonitrile solution.

\begin{tabular}{|l|c|c|c|c|}
\hline & Os(bpy) $_{3}{ }^{2+}$ & TAA-Os $^{\text {II }}$ & Os $^{\text {II }}$-AQ & TAA-Os $^{\text {II }}$-AQ \\
\hline Os(III/II) & 0.45 & 0.47 & 0.46 & 0.48 \\
\hline TAA $^{+/ 0}$ & & 0.30 & & 0.30 \\
\hline AQ $^{0 /-}$ & & & -1.29 & -1.28 \\
\hline bpy $^{0 /-}$ & -1.67 & -1.63 & -1.65 & -1.62 \\
\hline bpy $^{0 /-}$ & -1.86 & -1.84 & -1.85 & -1.83 \\
\hline bpy $^{0 /-}$ & -2.16 & -2.13 & -2.17 & -2.14 \\
\hline
\end{tabular}

All one-electron redox waves exhibit peak separations near the expected $59 \mathrm{mV}$. All redox waves exhibit current peak ratios near 1:1 when comparing the current peaks of oxidative and reductive sweeps.

The osmium data in Figure $3 \mathrm{~b}$ lead us to similar conclusions. Not surprisingly, the TAA, AQ, and bpy redox potentials are hardly affected by the change in metal (Table 2), only the metal oxidation process is susceptible to the replacement of $\mathrm{Ru}$ (II) by $\mathrm{Os}$ (II). The conversion of Os(II) to Os(III) occurs at $\sim 0.5 \mathrm{~V}$ vs. $\mathrm{Fc}^{+} / \mathrm{Fc}$, again in line with previous investigations. ${ }^{51}$ As noted above for ruthenium, reduction of the Os(bpy) ${ }_{3}{ }^{2+}$ complex occurs predominantly at the bpy ligands, but for convenience we will later designate the one-electron reduced osmium complex as $\mathrm{Os}^{\mathrm{I}}$.

The cyclic voltammograms for the iridium complexes in Figure $3 \mathrm{c}$ are less rich on the reductive side than the ruthenium and osmium data because there is only one (instead of three) ligand-based reduction processes in the potential window considered here. The wave at $-1.8 \mathrm{~V} \mathrm{vs.} \mathrm{Fc}^{+} / \mathrm{Fc}$ is assigned to a bpylocalized reduction process (Table 3$)$, whereas the 2-( $p$-tolyl)pyridine ligands are apparently reduced only at significantly more negative potentials. By analogy to what was noted above for ruthenium and 
osmium, below we will designate the reduced iridium complex as Ir ${ }^{\mathrm{II}}$. Oxidation of the metal complex occurs at $\sim 0.84 \mathrm{~V}$ vs. $\mathrm{Fc}^{+} / \mathrm{Fc}$, producing a species that will be designated as $\mathrm{Ir}^{\mathrm{IV}}$. This potential is $80 \mathrm{mV}$ lower for the iridium triad and dyads compared to that of the free Ir $^{\mathrm{III}}$ complex (second row of Table 3). For the ruthenium and osmium compounds the difference between the metal oxidation potentials of the free complexes and those of the dyads and triads ranges from 0 to $30 \mathrm{mV}$ (Tables 1 and 2). Thus, its seems that interaction of the iridium photosensitizing unit with the TAA and AQ moieties is somewhat stronger than in the case of the ruthenium and osmium dyads and triads. This finding is in line with those from optical absorption spectroscopy (see above). The electrochemical potentials of the organic redox-active moieties (TAA and AQ) are essentially the same in all the dyads and triads (Tables 1-3).

Table 3. Reduction potentials for the individual redox-active components of the iridium molecules from Scheme 2. All values were extracted from the data in Figure $3 \mathrm{c}$ and are reported versus the ferrocenium/ferrocene $\left(\mathrm{Fc}^{+} / \mathrm{Fc}\right)$ couple in acetonitrile solution.

\begin{tabular}{|l|c|c|c|c|}
\hline & Ir $^{\mathrm{II}}$ & TAA-Ir & Ir $^{\mathrm{II}}$-AQ & TAA-Ir $^{\mathrm{III}}$-AQ \\
\hline $\mathrm{Ir}(\mathrm{IV} / \mathrm{III})$ & 0.92 & 0.84 & 0.84 & 0.84 \\
\hline $\mathrm{TAA}^{+/ 0}$ & & 0.30 & & 0.30 \\
\hline $\mathrm{AQ}^{0 /-}$ & & & -1.28 & -1.26 \\
\hline $\mathrm{bpy}^{0 /-}$ & -1.79 & -1.76 & -1.80 & -1.75 \\
\hline
\end{tabular}

The bpy- and AQ-localized reductions exhibit good reversibility. TAA- and iridium-localized oneelectron oxidation waves show peak separations close to the expected $59 \mathrm{~mW}$, but the ratio between the current peaks in oxidative and reductive sweeps ranges from $\sim 1: 1$ to $\sim 40: 1$.

Based on the electrochemical data from Figure 3 and Tables $1-3$ one can establish the energy level diagram for the triads shown in Scheme 3. In doing so, we have neglected any effects arising from distance-dependent donor-acceptor interactions and have simply calculated energies for the individual states from differences in reduction potentials. ${ }^{58}$ This procedure obviously yields crude estimates at best, and even though we indicate energies to two digits of electron volts, we note that the error bars 
associated with these values are on the order of $0.1 \mathrm{eV}$. The energies of the emissive excited states of the individual metal complexes $(2.12 \mathrm{eV}, 1.79 \mathrm{eV}, 2.37 \mathrm{eV})$ represent the commonly used literature values. $^{11,31,38-39,51}$ In Scheme 3, these excited states are designated as $* \mathrm{Ru}^{\mathrm{II}}, * \mathrm{Os}^{\mathrm{II}}$, and $* \mathrm{Ir}^{\mathrm{III}}$.

Scheme 3. Energy level scheme showing the relevant photoexcited and charge-separated states which can be formed in the three triads from Scheme 2.

(a)

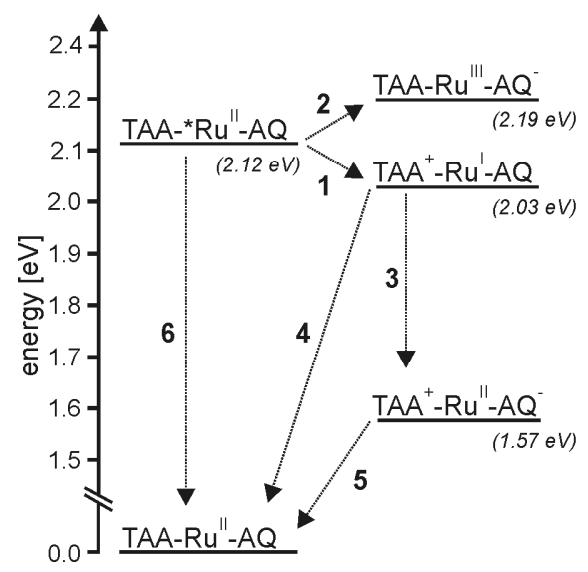

(b)

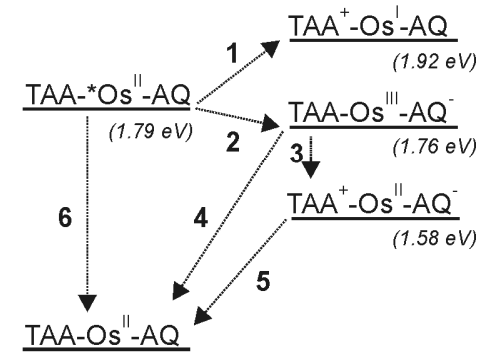

(c)

$\underline{\text { TAA-*|r' } \mid \text {-AQ }}$

$(2.37 \mathrm{eV})$

$\frac{T A A-\mid r^{I V}-A Q}{T A A^{+}-r^{\prime \prime}-A Q}(2.10 \mathrm{eV})$ $\underline{T^{\prime} A^{+}-I^{\prime \prime}-A Q}(2.05 \mathrm{eV})$ $\frac{T^{+} A^{+}-I^{\prime \prime \prime}-A Q^{-}}{(1.56 \mathrm{eV})}$ $\underline{\text { TAA-Ir"'-AQ }}$

Common to all three triads is the presence of a charge-separated state near $1.6 \mathrm{eV}$ containing oxidized triarylamine $\left(\mathrm{TAA}^{+}\right)$, the metal complex in its initial state $\left(\mathrm{Ru}^{\mathrm{II}}\right.$, Os ${ }^{\mathrm{II}}$, or $\left.\mathrm{Ir}^{\mathrm{III}}\right)$, and reduced anthraquinone $\left(\mathrm{AQ}^{-}\right)$. The energy of this final charge-separated state is obviously independent of the metal. Importantly, this state is energetically below all of the initially excited metal-localized emissive states, consequently, the final charge-separated state is energetically accessible irrespective of whether the ruthenium, osmium or iridium triad is considered.

In all three triads there are two possibilities for the formation of the final charge-separated state: (i) reductive quenching of the initially excited $* \mathrm{Ru}^{\mathrm{II}},{ }^{*} \mathrm{O}{ }^{\mathrm{II}}$, and $* \mathrm{Ir}^{\mathrm{III}}$ species by TAA, followed by electron transfer from the now reduced $\mathrm{Ru}^{\mathrm{I}}$, Os ${ }^{\mathrm{I}}$, or $\mathrm{Ir}^{\mathrm{II}}$ complexes to $\mathrm{AQ}$; or (ii) oxidative quenching of the initially excited $* \mathrm{Ru}^{\mathrm{II}},{ }^{*} \mathrm{Os}{ }^{\mathrm{II}}$, and $* \mathrm{Ir}^{\mathrm{III}}$ species by AQ, followed by electron transfer from TAA to the now oxidized $\mathrm{Ru}^{\mathrm{III}}$, Os ${ }^{\mathrm{III}}$, or $\mathrm{Ir}^{\mathrm{IV}}$ complexes. As seen from Scheme $3 \mathrm{a}$, in the ruthenium system possibility (i) is likely to dominate because the TAA ${ }^{+}-\mathrm{Ru}^{\mathrm{I}}-\mathrm{AQ}$ state at $2.03 \mathrm{eV}$ can be formed in an 
exergonic step from the initially excited TAA-*Ru ${ }^{\text {III }}-A Q$ level (at $2.12 \mathrm{eV}$ ), while formation of the TAA$\mathrm{Ru}^{\mathrm{III}}-\mathrm{AQ}^{-}$state (at $2.19 \mathrm{eV}$ ) is thermodynamically uphill. These thermodynamic considerations are consistent with the observation of a very weak emission quenching in the $\mathrm{Ru}^{\mathrm{II}}-\mathrm{AQ}$ dyad with respect to the $\mathrm{Ru}^{\mathrm{II}}$ reference complex (Figure $2 \mathrm{a}$ ), and a significant luminescence quenching in the TAA-Ru ${ }^{\mathrm{II}}$ dyad and TAA-Ru ${ }^{\text {II }}-\mathrm{AQ}$ triad relative to $\mathrm{Ru}^{\mathrm{II}}$.

In the case of the osmium triad (Scheme 3b) the thermodynamic situation is different and the oxidative quenching of the initially excited $* \mathrm{Os}^{\mathrm{II}}$ state is more probable: The TAA ${ }^{+}-\mathrm{Os}^{\mathrm{I}}-\mathrm{AQ}$ state is at $1.92 \mathrm{eV}$, that is roughly $0.13 \mathrm{eV}$ above the initially excited ${ }^{3}$ MLCT state. By contrast, the TAA-Os ${ }^{\mathrm{II}}$ $\mathrm{AQ}^{-}$level is at $1.76 \mathrm{eV}$, energetically close to the lowest ${ }^{3} \mathrm{MLCT}$ state of the Os(bpy) ${ }_{3}{ }^{2+}$ unit (at 1.79 $\mathrm{eV}$ ), hence the oxidative quenching appears thermodynamically more viable than the reductive quenching. Again, the luminescence data from Figure 2 are consistent with our energetic considerations: The emission intensity of the molecules containing AQ (Os ${ }^{\mathrm{II}}-\mathrm{AQ}$ dyad and TAA-Os ${ }^{\mathrm{II}}-\mathrm{AQ}$ triad) are weaker than those of the molecules that do not contain this oxidant (Os ${ }^{\mathrm{II}}$, TAA-Os ${ }^{\mathrm{II}}$ dyad), supporting the hypothesis that excited-state deactivation by electron transfer to anthraquinone is a more efficient process than reductive excited-state quenching by triarylamine in this case.

For the iridium triad both the oxidative and reductive excited-state quenching processes are thermodynamically downhill from the initial TAA-*Ir ${ }^{\mathrm{III}}-\mathrm{AQ}$ state at $2.37 \mathrm{eV}$ : The TAA-Ir ${ }^{\mathrm{IV}}-\mathrm{AQ}^{-}$level is estimated to be at $2.10 \mathrm{eV}$, the $\mathrm{TAA}^{+}-\mathrm{Ir}^{\mathrm{II}}-\mathrm{AQ}$ state is calculated to lie at $2.05 \mathrm{eV}$. The observation of strong emission quenchings in both iridium dyads (including the triad) relative to the Ir $^{\mathrm{III}}$ reference complex is consistent with this energy level structure: irrespective of whether TAA or AQ is attached to the metal complex nonradiative excited-state deactivation becomes efficient.

Nanosecond transient absorption. Figure 4 provides direct experimental evidences for the formation of the final charge-separated states containing oxidized TAA and reduced AQ. The series of transient absorption spectra shown in Figure $4 a-c$ was measured using $\sim 10^{-5} \mathrm{M}$ solutions of the TAA-Ru ${ }^{\text {II }}$-AQ (a), TAA-Os ${ }^{\text {II }}$-AQ (b), TAA-Ir ${ }^{\mathrm{III}}$-AQ (c) triads in de-oxygenated acetonitrile. 
Figure 4. Panels (a) - (c) show transient absorption spectra measured on $\mathrm{CH}_{3} \mathrm{CN}$ solutions of TAA$\mathrm{Ru}^{\mathrm{II}}-\mathrm{AQ}$ (a), TAA-Os ${ }^{\mathrm{II}}-\mathrm{AQ}$ (b), and TAA-Ir ${ }^{\mathrm{II}}-\mathrm{AQ}$ (c) in a 200-ns time window starting immediately after excitation with 10-ns laser pulses at $532 \mathrm{~nm}(\mathrm{a}, \mathrm{b})$ or $355 \mathrm{~nm}$ (c). Panel (d) shows a series of absorption spectra from a $\mathrm{CH}_{2} \mathrm{Cl}_{2}$ solution of a triarylamine reference molecule (structure shown in the inset) after increasing time intervals following application of an electrochemical potential more positive than $0.5 \mathrm{~V}$ vs. $\mathrm{Fc}^{+} / \mathrm{Fc}$ (in presence of $0.1 \mathrm{M} \mathrm{TBAPF}_{6}$ ). Panel (e) shows a series of absorption spectra obtained from a $\mathrm{CH}_{2} \mathrm{Cl}_{2}$ solution of 9,10-anthraquinone obtained in an analogous spectroelectrochemical experiment using potentials more negative than $-1.2 \mathrm{~V}$ vs. $\mathrm{Fc}^{+} / \mathrm{Fc}$.

In the case of the ruthenium and osmium systems excitation occurred at $532 \mathrm{~nm}$, while the iridium compound was excited at $355 \mathrm{~nm}$. In all cases the laser pulses had a width of $\sim 10 \mathrm{~ns}$. Detection took place in a time window of $200 \mathrm{~ns}$ starting immediately after the laser pulses. Under these experimental conditions, one obtains similar transient absorption spectra for all three triads. In each of the three spectra (Figure 4a-c) there are three bands with maxima near $380 \mathrm{~nm}, 565 \mathrm{~nm}$, and $770 \mathrm{~nm}$. Based on 
the spectro-electrochemical data in Figure $4 \mathrm{~d}$ and Figure $4 \mathrm{e}$ the three bands can be readily assigned. Figure $4 \mathrm{~d}$ shows a series of absorption spectra which were obtained while applying an electrochemical potential more positive than $0.5 \mathrm{~V}$ vs. $\mathrm{Fc}^{+} / \mathrm{Fc}$ to a $\mathrm{CH}_{2} \mathrm{Cl}_{2}$ solution of a triarylamine reference molecule (chemical structure shown in the inset). From this series of spectra (obtained after different time intervals after initiating the oxidation process; using $0.1 \mathrm{M} \mathrm{TBAPF}$ as an electrolyte) we learn that the transient absorption band located around $770 \mathrm{~nm}$ is due to the oxidized amine. ${ }^{35-36,55,59-60}$ The absorption spectra in Figure 4e were measured while applying an electrochemical potential more negative than $-1.2 \mathrm{~V}$ vs. $\mathrm{Fc}^{+} / \mathrm{Fc}$ to a $\mathrm{CH}_{2} \mathrm{Cl}_{2}$ solution of 9,10 -anthraquinone in presence of $0.1 \mathrm{M}$ $\mathrm{TBAPF}_{6}$. From this series of spectra we learn that the transient absorption bands located at $380 \mathrm{~nm}$ and $565 \mathrm{~nm}$ are due to reduced anthraquinone. ${ }^{19,56,61-62}$ Thus, the observation of a fully charge-separated state in all three triads is beyond question, and this finding is in line with the energy level diagram from Scheme 3, in which we have come to the conclusion that such a final charge-separated state is thermodynamically accessible from the initially excited metal-localized state in all three triads.

Figure 5 shows the decays of the transient absorption intensities at $380 \mathrm{~nm}$ (black traces), $565 \mathrm{~nm}$ (blue traces), and $770 \mathrm{~nm}$ (green traces) in de-oxygenated acetonitrile solution. In all the three triads we observe decays which are single exponential over at least one order of magnitude, and in all cases the decays at the three abovementioned wavelengths yield nearly identical lifetimes. This is consistent with the notion that the $\mathrm{TAA}^{+}$and $\mathrm{AQ}^{-}$species disappear jointly in a thermal charge-recombination event. The average lifetimes of the fully charge-separated states extracted from fits to the experimental decay data in Figure 5 are $1.3 \mu$ in the case of the $\mathrm{TAA}^{+}-\mathrm{Ru}^{\mathrm{II}}-\mathrm{AQ}^{-}$state, ${ }^{29} 80 \mathrm{~ns}$ for the $\mathrm{TAA}^{+}-\mathrm{Os}^{\mathrm{II}}-\mathrm{AQ}^{-}$state, and $890 \mathrm{~ns}$ in the case of the $\mathrm{TAA}^{+}-\mathrm{Ir}^{\mathrm{III}}-\mathrm{AQ}^{-}$state (all in de-oxygenated $\mathrm{CH}_{3} \mathrm{CN}$ at $\left.25^{\circ} \mathrm{C}\right) .^{63}$

Given the fact that the final charge-separated state involves electron-hole separation formally over a 22- $\AA$ distance, a lifetime in the 100 -ns- to $\mu$ s-regime is not particularly surprising, ${ }^{1}$ even if the effective electron transfer distance may be somewhat shorter as a consequence of partial hole or electron delocalization onto the $p$-xylene bridging elements. ${ }^{64-66}$ What is surprising, however, is the observation of a markedly shorter lifetime for the osmium triad compared to the ruthenium and iridium systems. We 
can only speculate what the origin of this effect might be, but it seems possible that the energetic proximity of the TAA-Os ${ }^{\mathrm{III}}-\mathrm{AQ}^{-}$state, only $0.18 \mathrm{eV}$ above the final charge-separated state, may play a role. In the ruthenium and iridium triads the final charge-separated states are energetically well below all the other states $(>0.45 \mathrm{eV})$, hence thermal one-step back-electron transfers might be less likely to occur in these systems than in the osmium triad. Be that as it may, we conclude from this section that the final charge-separated states containing $\mathrm{TAA}^{+}$cations and $\mathrm{AQ}^{-}$anions are formed in all the three triads from Scheme 2. In the following we focus on the kinetics and quantum yields of their formation.
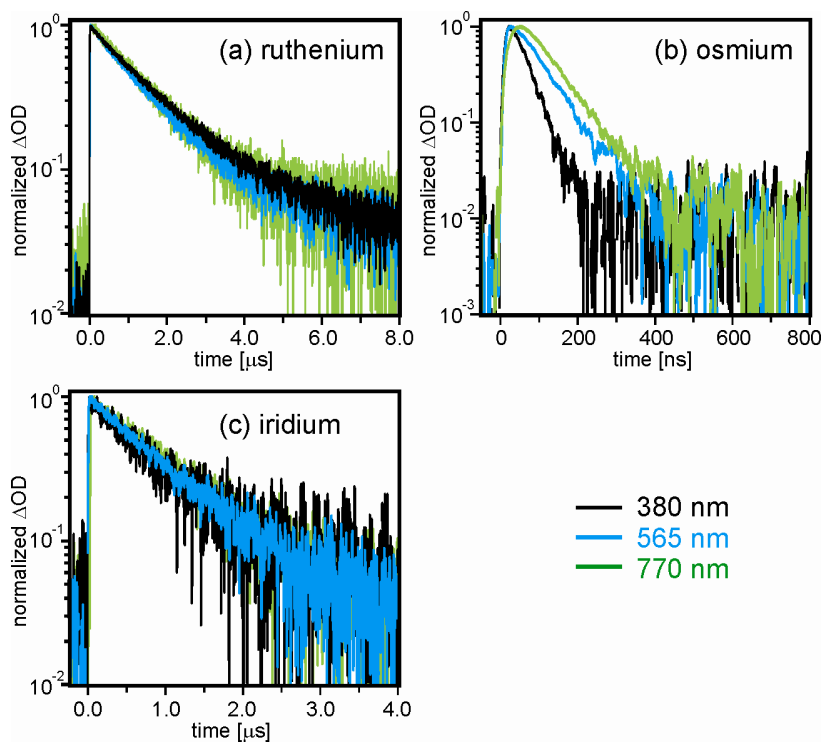

Figure 5. Decays of the transient absorption intensities from Figure 4 at three different wavelengths in the TAA-Ru ${ }^{\mathrm{II}}-\mathrm{AQ}(\mathrm{a})$, TAA-Os ${ }^{\mathrm{II}}-\mathrm{AQ}(\mathrm{b})$, and TAA-Ir ${ }^{\mathrm{III}}$-AQ (c) triads in de-oxygenated $\mathrm{CH}_{3} \mathrm{CN}$ solution at $25^{\circ} \mathrm{C}$. Excitation occurred at $532 \mathrm{~nm}$ for the ruthenium and osmium triads and at $355 \mathrm{~nm}$ for the iridium system.

\section{Kinetics and quantum yields for formation of charge-separated states in the ruthenium triad.}

Figure 6a shows the build-up of the transient absorption intensity at $770 \mathrm{~nm}$ after photoexcitation of the TAA-Ru ${ }^{\text {II }}-\mathrm{AQ}$ triad in acetonitrile at $400 \mathrm{~nm}$. The pulse width in this case was $150 \mathrm{fs}$, hence we are able to monitor the formation of $\mathrm{TAA}^{+}$at high temporal resolution in this experiment. The risetime for this 
transient absorption is $9 \mathrm{ps}$, and we may conclude that the TAA ${ }^{+}-\mathrm{Ru}^{\mathrm{I}}-\mathrm{AQ}$ state at $2.03 \mathrm{eV}$ is formed with a time constant of $1.1 \times 10^{11} \mathrm{~s}^{-1}$ from the initially excited TAA-*Ru ${ }^{\mathrm{II}}-\mathrm{AQ}$ state at $2.12 \mathrm{eV}$. In Scheme 3 and Table 4 this particular electron transfer event, corresponding to a reductive $\mathrm{Ru}(\mathrm{bpy}){ }_{3}{ }^{2+}{ }^{3} \mathrm{MLCT}$ excited-state quenching by TAA, is denoted as process “ 1 ".
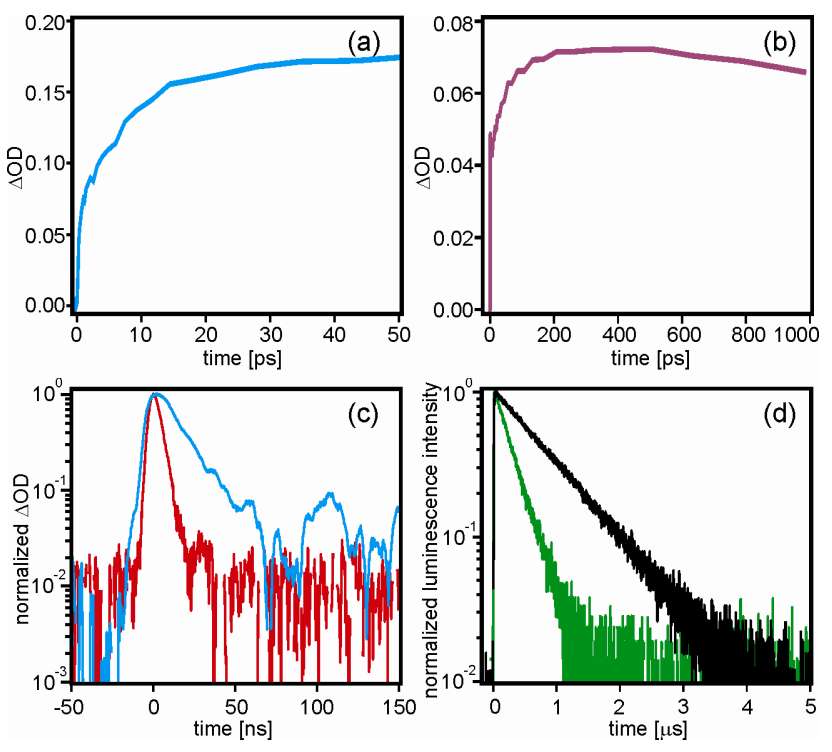

Figure 6. (a) Temporal evolution of the transient absorption signal at $770 \mathrm{~nm}\left(\mathrm{TAA}^{+}\right.$formation) after excitation of the TAA-Ru ${ }^{\text {II }}$-AQ triad at $400 \mathrm{~nm}$ with laser pulses of $150 \mathrm{fs}$ width. (b) Time profile for the

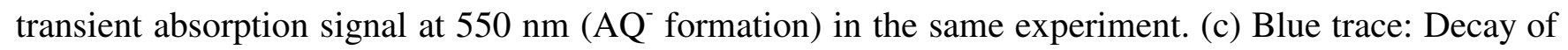
the $\mathrm{TAA}^{+}$absorption at $770 \mathrm{~nm}$ in the TAA-Ru ${ }^{\mathrm{II}}$ dyad after excitation at $450 \mathrm{~nm}$ with $\sim 10$-ns laser pulses. Red trace: Instrument response curve. (d) Black trace: Decay of the luminescence emitted by $\mathrm{Ru}^{\mathrm{II}}$ at $610 \mathrm{~nm}$ in de-oxygenated $\mathrm{CH}_{3} \mathrm{CN}$ after excitation at $450 \mathrm{~nm}$; green trace: decay of the same luminescence in $\mathrm{Ru}^{\mathrm{II}}$-AQ in de-oxygenated $\mathrm{CH}_{3} \mathrm{CN}$.

Figure $6 \mathrm{~b}$ shows the temporal evolution of the transient absorption intensity for the same sample as in Figure $6 \mathrm{a}$ and in the same experiment, but at $550 \mathrm{~nm}$. The risetime in this case is $50 \mathrm{ps}$, and we conclude that $\mathrm{AQ}^{-}$is formed with a time constant of $2 \cdot 10^{10} \mathrm{~s}^{-1}$. Given the rapid kinetics for the formation of the $\mathrm{TAA}^{+}-\mathrm{Ru}$-AQ state at $2.03 \mathrm{eV}$, a time constant of $2 \cdot 10^{10} \mathrm{~s}^{-1}$ is attributed to the process " 3 " in Scheme 3 , 
i. e., the electron transfer from $\mathrm{Ru}^{\mathrm{I}}$ to $\mathrm{AQ}$ while maintaining the hole at the $\mathrm{TAA}^{+}$site. Already after $\sim 200$ ps the transient absorption intensities at $770 \mathrm{~nm}$ and $550 \mathrm{~nm}$ have both reached their maxima, indicating that the final charge-separated state $\left(\mathrm{TAA}^{+}-\mathrm{Ru}^{\mathrm{II}}-\mathrm{AQ}^{-}\right)$at $1.57 \mathrm{eV}$ is completely formed at this point. As discussed in the prior section, this state has a lifetime of $1.3 \mu$ s in de-oxygenated $\mathrm{CH}_{3} \mathrm{CN}_{\text {, }}$ corresponding to a rate constant of $7.7 \cdot 10^{5} \mathrm{~s}^{-1}$ for process " 5 " in Scheme $3 \mathrm{a}$ (Table 4).

Table 4. Rate constants for the individual intramolecular processes shown in Scheme 3 and Scheme 4 as extracted from the data in Figure 5 - Figure 8 (de-oxygenated $\mathrm{CH}_{3} \mathrm{CN}$ solution, $25^{\circ} \mathrm{C}$ ).

\begin{tabular}{|c|c|c|c|}
\hline $\begin{array}{c}\text { reaction } \\
\text { step no. }\end{array}$ & TAA-Ru ${ }^{\text {II }}$-AQ & TAA-Os ${ }^{\text {II }}$-AQ & TAA-Ir ${ }^{\text {III-AQ }}$ \\
\hline 1 & $1.1 \cdot 10^{11} \mathrm{~s}^{-1}$ & $<5.3 \cdot 10^{6} \mathrm{~s}^{-1}$ & $3.5 \cdot 10^{12} \mathrm{~s}^{-1}$ \\
\hline 2 & $2.1 \cdot 10^{6} \mathrm{~s}^{-1}$ & $\sim 10^{8} \mathrm{~s}^{-1}$ & $3.3 \cdot 10^{11} \mathrm{~s}^{-1}$ \\
\hline 3 & $2.0 \cdot 10^{10} \mathrm{~s}^{-1}$ & $\sim 10^{8} \mathrm{~s}^{-1}$ & $2.5 \cdot 10^{10} \mathrm{~s}^{-1}$ \\
\hline 4 & $6.7 \cdot 10^{7} \mathrm{~s}^{-1}$ & $3.8 \cdot 10^{7} \mathrm{~s}^{-1}$ & $1.5 \cdot 10^{7} \mathrm{~s}^{-1}$ \\
\hline 5 & $7.7 \cdot 10^{5} \mathrm{~s}^{-1}$ & $1.3 \cdot 10^{7} \mathrm{~s}^{-1}$ & $1.1 \cdot 10^{6} \mathrm{~s}^{-1}$ \\
\hline 6 & $1.2 \cdot 10^{6} \mathrm{~s}^{-1}$ & $5.3 \cdot 10^{7} \mathrm{~s}^{-1}$ & $4.4 \cdot 10^{6} \mathrm{~s}^{-1}$ \\
\hline
\end{tabular}

${ }^{a}$ Refers to the reaction steps marked by the numbered arrows in Scheme 3 and Scheme 4.

In the $\mathrm{TAA}-\mathrm{Ru}{ }^{\mathrm{II}}$ dyad, the $\mathrm{TAA}^{+}$radical cation absorption at $770 \mathrm{~nm}$ decays with a lifetime of $15 \mathrm{~ns}$ (blue trace in Figure 6c). We infer from this observation, that in the triad process "4" (Scheme 3a) proceeds with a rate constant of $6.7 \cdot 10^{7} \mathrm{~s}^{-1}$. Thus, once the TAA ${ }^{+}-\mathrm{Ru}^{\mathrm{I}}-\mathrm{AQ}$ state at $2.03 \mathrm{eV}$ is formed, the system is much more likely to undergo ruthenium-to-anthraquinone electron transfer $\left(\mathrm{k}_{3}=2 \cdot 10^{10} \mathrm{~s}^{-1}\right)$ than ruthenium-to-triarylamine back-electron transfer $\left(\mathrm{k}_{4}=6.7 \cdot 10^{7} \mathrm{~s}^{-1}\right)$.

In order to estimate the quantum yield for the formation of the $\mathrm{TAA}^{+}-\mathrm{Ru}^{\mathrm{II}}-\mathrm{AQ}^{-}$state at $1.57 \mathrm{eV}$ out of the initially excited TAA-*Ru ${ }^{\text {II }}-\mathrm{AQ}$ state, two pieces of information are yet missing: (i) the rate constant for the reductive excited-state quenching to form the TAA-Ru ${ }^{\text {III }}-\mathrm{AQ}^{-}$state at $2.19 \mathrm{eV}$ (process " 2 " in Scheme 3a), and (ii) the decay rate constant of the Ru(bpy) ${ }_{3}{ }^{2+}{ }^{3} \mathrm{MLCT}$ excited state (process " 6 " in 
Scheme 3a). The rate constant for the process "6" may simply be estimated from the lifetime of the isolated $\mathrm{Ru}(\mathrm{bpy})_{3}{ }^{2+}$ complex in de-oxygenated acetonitrile $\left(1.2 \cdot 10^{6} \mathrm{~s}^{-1}\right)$. The rate constant for the process "2" is more difficult to obtain. We have found that the only viable possibility in this case involves the use of time-resolved luminescence spectroscopy: Figure 6d compares the luminescence decays of the $\mathrm{Ru}^{\mathrm{II}}$ reference complex (black trace) and the $\mathrm{Ru}$ - $\mathrm{AQ}$ dyad (green trace), detected at $610 \mathrm{~nm}$ after the excitation at $532 \mathrm{~nm}$ with laser pulses of $\sim 10 \mathrm{~ns}$ width. The luminescence decays with a lifetime of 830 ns in the case of the reference complex, and with a lifetime of $300 \mathrm{~ns}$ in the case of the Ru ${ }^{\mathrm{II}}-\mathrm{AQ}$ dyad. The difference between the two luminescence decay rate constants $\left(2.1 \cdot 10^{6} \mathrm{~s}^{-1}\right)$ is taken as the rate constant for the process " 2 " in Scheme 3. Unfortunately, the $\mathrm{AQ}^{-}$anion cannot be detected for the Ru II $_{-}$ AQ dyad, ${ }^{57}$ presumably because of rapid thermal back-electron transfer in the opposite sense; this appears to be not an uncommon problem for ruthenium-quinone dyads. ${ }^{25,57}$ In the triad, $\mathrm{AQ}^{-}$is formed after $\mathrm{TAA}^{+}(50$ ps vs. 9 ps, see above), hence in the picosecond transient absorption data (Figure 6a, b) one observes the formation of the final charge-separated state at $1.57 \mathrm{eV}$ rather than the TAA-Ru ${ }^{\mathrm{III}}-\mathrm{AQ}^{-}$ state at $2.19 \mathrm{eV}$.

With numerical estimates for the rate constants of the processes "1" - "6" from Scheme $3 a$ at hand (second column of Table 4), we estimate a quantum yield of $99.7 \%$ for the formation of the final charge-separated state. Essentially every photon put into the $\mathrm{Ru}(\mathrm{bpy})_{3}{ }^{2+} \mathrm{MLCT}$ state at $2.12 \mathrm{eV}$ thus leads to the formation of a molecule in the $\mathrm{TAA}^{+}-\mathrm{Ru}^{\mathrm{II}}-\mathrm{AQ}^{-}$state at $1.57 \mathrm{eV}$.

\section{Kinetics and quantum yields for formation of charge-separated states in the osmium triad. In the} case of the osmium triad a completely different situation is encountered. The reductive excited-state quenching by TAA is endergonic in this sample, and we have been unable to find any evidence for the formation of the $\mathrm{TAA}^{+}-\mathrm{Os}^{\mathrm{I}}-\mathrm{AQ}$ state at $1.92 \mathrm{eV}$, both from investigations of the TAA-Os ${ }^{\mathrm{II}}$ dyad and the TAA-Os ${ }^{\text {II }}$-AQ triad, in the pico- to millisecond time regimes. We conclude from this observation that the rate constant for the process " 1 " in Scheme $3 b$ amounts to less than 10 percent of the inherent 
Os(bpy) ${ }_{3}^{2+3}$ MLCT decay rate constant, which is $5.3 \cdot 10^{7} \mathrm{~s}^{-1}$ under these experimental conditions (deoxygenated $\mathrm{CH}_{3} \mathrm{CN}$ at room temperature; process "6" in Scheme $\left.3 \mathrm{~b}\right) .{ }^{51}$
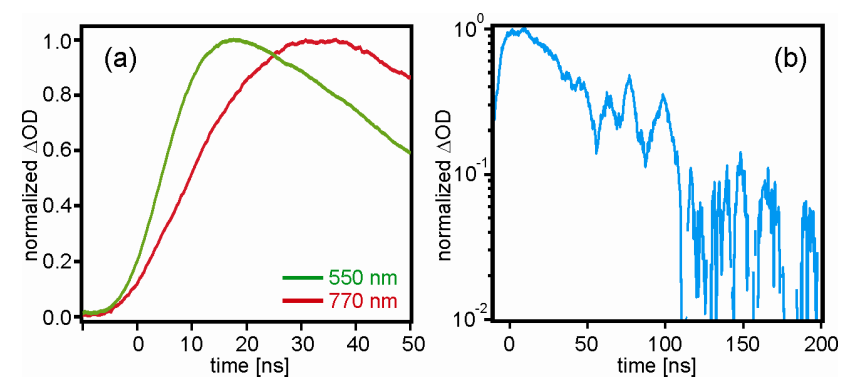

Figure 7. (a) Rise of the transient absorption signals at $550 \mathrm{~nm}$ (green trace) and $770 \mathrm{~nm}$ (red trace) after excitation of the TAA-Os ${ }^{\mathrm{II}}$-AQ triad at $532 \mathrm{~nm}$ with laser pulses of $\sim 10 \mathrm{~ns}$ width $\left(\mathrm{CH}_{3} \mathrm{CN}\right.$ solution). (b) Decay of the transient absorption signal of the Os ${ }^{\mathrm{II}}-\mathrm{AQ}$ dyad at $550 \mathrm{~nm}$ ( $\mathrm{AQ}^{-}$disappearance) after excitation at $532 \mathrm{~nm}$ with laser pulses of $\sim 10 \mathrm{~ns}$ width (de-oxygenated $\mathrm{CH}_{3} \mathrm{CN}$ solution).

In transient absorption experiments performed with the Os ${ }^{\mathrm{II}}-\mathrm{AQ}$ dyad and the TAA-Os ${ }^{\mathrm{II}}-\mathrm{AQ}$ triad, the radical anion of AQ (monitored at $550 \mathrm{~nm}$ ) is formed with a time constant of $\sim 10 \mathrm{~ns}$ (Figure 7a, green trace). There is a technical problem associated with this finding: on the one hand, $10 \mathrm{~ns}$ is too long to be measured accurately with our femtosecond equipment, and on the other hand, $10 \mathrm{~ns}$ is too short to be detected on our nanosecond setup with reliable accuracy. In this awkward situation we tentatively attribute a rate constant of $\sim 10^{8} \mathrm{~s}^{-1}$ to the process " 2 " from Scheme $3 \mathrm{~b}$, but note that error bars are rather large in this particular case.

In the OsI ${ }^{\mathrm{II}}-\mathrm{AQ}$ dyad the $\mathrm{AQ}^{-}$signal at $550 \mathrm{~nm}$ decays with a time constant of $26 \mathrm{~ns}$ (Figure 7b), and consequently we estimate a rate constant of $3.8 \cdot 10^{7} \mathrm{~s}^{-1}$ for the process " 4 " in Scheme $3 \mathrm{~b}$, which corresponds to back-electron transfer from reduced anthraquinone to Os ${ }^{\mathrm{III}}$.

For the TAA-Os ${ }^{\mathrm{II}}$-AQ triad the transient absorption intensity at $770 \mathrm{~nm}$, due to $\mathrm{TAA}^{+}$, builds up with a time constant of $20 \mathrm{~ns}$ (Figure 7a, red trace). Assuming the process " 2 " has $k_{2} \approx 10^{8} \mathrm{~s}^{-1}$ and further assuming that the TAA-Os ${ }^{\mathrm{III}}-\mathrm{AQ}^{-}$state at $1.76 \mathrm{eV}$ must be formed before the fully charge-separated state is accessible, we arrive at the conclusion that the rate constant for the process " 3 " is $\sim 10^{8} \mathrm{~s}^{-1}$. The TAA ${ }^{+}$ 
$\mathrm{Os}^{\mathrm{II}}-\mathrm{AQ}^{-}$state at $1.58 \mathrm{eV}$ then decays with a lifetime of $80 \mathrm{~ns}$ (see prior section), corresponding to a rate constant of $1.3 \cdot 10^{7} \mathrm{~s}^{-1}$ for the process " 5 " in Scheme $3 \mathrm{~b}$. The complete set of rate constants for the TAAOs ${ }^{\text {II }}$-AQ triad in the third column of Table 4 leads us to the conclusion that the fully charge-separated state is formed with a quantum yield of $\sim 46 \%$ out of the initially excited Os(bpy $)_{3}{ }^{2+}$ MLCT state.

\section{Kinetics and quantum yields for formation of charge-separated states in the iridium triad. For} the iridium triad the situation is fundamentally different from that for the ruthenium and osmium triads: we were unable to selectively excite the metal complex in TAA-Ir ${ }^{\mathrm{III}}$-AQ. Even at the comparatively long wavelength of $420 \mathrm{~nm}$, there is an absorption from the organic moieties; this is particularly evident from a comparison of the (ground-state) absorption spectrum of the $\operatorname{Ir}^{\mathrm{III}}$ reference complex with those of the TAA-Ir ${ }^{\mathrm{III}}$ dyad and the TAA-Ir ${ }^{\mathrm{III}}$-AQ triad (Figure 1c). Instead of Scheme 3c, we therefore use an energy level diagram for the TAA-Ir ${ }^{\mathrm{III}}$-AQ triad which has been adapted to reflect this additional complication (Scheme 4). In this more complex scheme we introduce an additional state named $*\left(T A A-\mathrm{Ir}^{\mathrm{III}}\right)-\mathrm{AQ}$, which is supposed to reflect the possibility that initial excitation may involve the entire triarylamineiridium(III) fragment and not just solely the $\mathrm{Ir}^{\mathrm{III}}$ complex. In addition to the evidence from absorption spectra, evidence for electronic interaction between the iridium complex and TAA was obtained from the electrochemical measurements, where a clear shift in the iridium oxidation potential was observed for the dyads and the triad (see above). Furthermore, in Scheme 4 we omit the TAA- $\mathrm{Ir}^{\mathrm{IV}}-\mathrm{AQ}^{-}$state at $2.10 \mathrm{eV}$ because there is no experimental evidence for its formation in the triad, see below.

Scheme 4. Energy level scheme showing the relevant photoexcited and charge-separated states which can be formed in the iridium triad. 

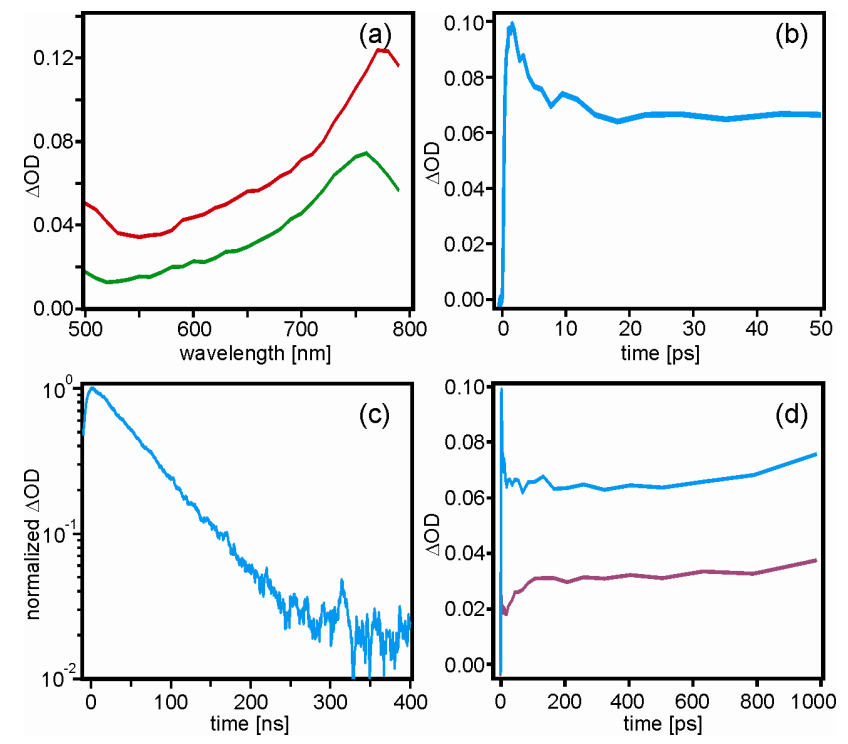

The red trace in Figure $8 \mathrm{a}$ is the transient absorption spectrum detected with a delay of 1 ps after the excitation of TAA- $\mathrm{Ir}^{\mathrm{III}}$-AQ in $\mathrm{CH}_{3} \mathrm{CN}$ at $420 \mathrm{~nm}$. This spectrum shows an absorption band at $770 \mathrm{~nm}$, which we have identified above as due to $\mathrm{TAA}^{+}$. There is an additional absorption between $500 \mathrm{~nm}$ and $650 \mathrm{~nm}$, which cannot be accounted for by the oxidized triarylamine unit (compare to Figure 4d). It appears plausible to attribute this additional absorption to the reduced metal complex, i. e., the Ir $^{\text {II }}$ species. In the TAA-Ir ${ }^{\mathrm{III}}$ dyad a similar transient absorption spectrum can be detected in a 200-ns time window starting immediately after a 10-ns laser pulse (data not shown).

Figure 8. (a) Red trace: Transient absorption spectrum detected with a delay of 1 ps after excitation of an acetonitrile solution of TAA-Ir ${ }^{\mathrm{III}}$-AQ at $420 \mathrm{~nm}$; green trace: transient absorption spectrum from the 
same sample detected with a delay of 3 ps. (b) Time profile of the transient absorption at $770 \mathrm{~nm}$ from the same sample after excitation at $420 \mathrm{~nm}$ with laser pulses of $150 \mathrm{fs}$ width. (c) Decay of the transient absorption at $770 \mathrm{~nm}$ after excitation of the TAA-Ir ${ }^{\mathrm{III}}$ dyad (in de-oxygenated $\mathrm{CH}_{3} \mathrm{CN}$ ) at $355 \mathrm{~nm}$ with 10-ns laser pulses. (d) Time profiles of the transient absorption at $550 \mathrm{~nm}$ (purple trace) and $770 \mathrm{~nm}$ (blue trace) after 420-nm excitation of the TAA-Ir ${ }^{\mathrm{II}}$-AQ triad in $\mathrm{CH}_{3} \mathrm{CN}$ (laser pulse width: $150 \mathrm{fs}$ ).

The time profile of the optical density at $770 \mathrm{~nm}$ after excitation of the iridium triad at $420 \mathrm{~nm}$ with femtosecond laser pulses is shown in Figure 8b. From the initial rise we extract a time constant of 0.4 ps. Subsequently, there is a decrease in the $\triangle \mathrm{OD}$ at this detection wavelength, occurring with a time constant of 3 ps. The spectral changes that occur in this time regime are minor (green trace in Figure 8a), hence the electronic states formed after 0.4 ps (red trace in Figure 8a) and 3 ps (green trace in Figure 8a) must be chemically very similar to each other. In Scheme 4 we designate the state formed after 0.4 ps as $*\left(\mathrm{TAA}^{+}-\mathrm{Ir}^{\mathrm{II}}\right)-\mathrm{AQ}$, while the state formed after $3 \mathrm{ps}$ is denoted as TAA ${ }^{+}-\mathrm{Ir}^{\mathrm{II}}-\mathrm{AQ}$. In other words, after 0.4 ps a charge-separated state is already formed, but this state undergoes subsequent electronic relaxation with a time constant of 3 ps. In our opinion, this explanation makes sense in view of the fact that photoexcitation of the TAA-Ir ${ }^{\mathrm{III}}$-AQ triad (contrary to the ruthenium and osmium systems) cannot occur selectively at the metal center but seems to involve the entire TAA-Ir ${ }^{\mathrm{III}}$ fragment, see above. Thus, in Scheme 4 we attribute a rate constant of $3.5 \cdot 10^{12} \mathrm{~s}^{-1}$ to process " 1 " and a rate constant of $3.3 \cdot 10^{11} \mathrm{~s}^{-1}$ to process "2" (last column of Table 4).

Once formed, the relaxed $\mathrm{TAA}^{+}-\mathrm{Ir}^{\mathrm{II}}-\mathrm{AQ}$ state at $2.05 \mathrm{eV}$ can either undergo charge-recombination to the ground state (process " 4 " in Scheme 4) or it can proceed to the final charge-separated state at 1.56 eV (process "3"). Experiments on the TAA-Ir" dyad indicate that the back-electron transfer between the oxidized TAA and reduced iridium takes place with a time constant of $67 \mathrm{~ns}$; the respective transient absorption decay data is shown in Figure 8c. We infer that in the triad the process " 4 " occurs with a rate constant of $1.5 \cdot 10^{7} \mathrm{~s}^{-1}$ (last column of Table 4 ). 
Kinetic information regarding the formation of the fully charge-separated state at $1.56 \mathrm{eV}$ can be extracted from the purple trace in Figure 8d, which shows the time profile of the optical density at 550 $\mathrm{nm}$, i. e., at one of the absorption band maxima of the $\mathrm{AQ}^{-}$species. The respective time profile shows an initial rapid rise and a decay due to the formation of the *(TAA $\left.{ }^{+}-\mathrm{Ir}^{\mathrm{II}}\right)-\mathrm{AQ}$ and $\mathrm{TAA}{ }^{+}-\mathrm{Ir}^{\mathrm{II}}-\mathrm{AQ}$ states, which also absorb at this wavelength (Figure 8a). Subsequently, there is a slower rise with a time constant of $40 \mathrm{ps,}$ which is attributed to the build-up of the $\mathrm{TAA}^{+}-\mathrm{Ir}^{\mathrm{III}}-\mathrm{AQ}^{-}$population. At the same time the optical density at $770 \mathrm{~nm}$ stays essentially constant (blue trace in Figure 8d), consistent with the formation of the fully charge-separated state. A rate constant of $2.5 \cdot 10^{10} \mathrm{~s}^{-1}$ is therefore attributed to the process "3" in Scheme 4.

The rate constant for the process " 5 ", i. e., thermal charge-recombination from the TAA $-\mathrm{Ir}^{\mathrm{III}}-\mathrm{AQ}^{-}$ state at $1.56 \mathrm{eV}$ is $1.1 \cdot 10^{6} \mathrm{~s}^{-1}$ (lifetime of $890 \mathrm{~ns}$, see prior section). The rate constant for the process " 6 ", i. e., relaxation of the photoexcited iridium complex to the electronic ground state is estimated from the luminescence lifetime of the $\mathrm{Ir}^{\mathrm{III}}$ reference complex (230 ns in oxygen-free acetonitrile; $k_{6}=4.4 \cdot 10^{6} \mathrm{~s}^{-}$ $1)^{31}$

Based on the rate constants for the individual photophysical and photochemical processes in Scheme 4 (last column of Table 4), we arrive at the conclusion that the fully charge-separated state is formed in essentially quantitative yield from the initially photoexcited state.

\section{SUMMARY AND CONCLUSIONS}

Final charge-separated states containing an oxidized triarylamine fragment and a reduced anthraquinone moiety are formed in all three triads from Scheme 2, albeit with different quantum yields and via differing reaction mechanisms involving different kinetics. The thermodynamics of the photoinduced charge-separation steps are such that reductive quenching of the initially excited ruthenium state is clearly favored kinetically, while oxidative quenching is predominant in the case of 
the osmium system. In the iridium triad both the reductive and oxidative excited-state quenching steps are thermodynamically possible, but the reductive pathway dominates kinetically. In the ruthenium and iridium systems the driving-forces associated with the formation of initial charge-separated states are sufficiently large to make photoinduced electron transfer the dominant excited-state deactivation pathway, particularly in view of the comparatively long ${ }^{3}$ MLCT lifetimes of the Ru(bpy) ${ }^{2+}$ and $[\operatorname{Ir}(2-(p-$ tolyl)pyridine $\left.)_{2}(\mathrm{bpy})\right]^{+}$photosensitizers. From the initial charge-separated states, the formation of the final charge-separated state is kinetically favored versus thermal recombination in all three cases, which may be a manifestation of an inverted driving-force effect. ${ }^{47,67}$ These favorable circumstances lead to the formation of the final charge-separated state with quantum yields near unity, at least in the case of the ruthenium and iridium systems. The osmium triad, by contrast, suffers from a much shorter ${ }^{3}$ MLCT lifetime of the $\mathrm{Os}(\mathrm{bpy})_{3}{ }^{2+}$ sensitizer and a significantly lower driving-force for formation of the initial charge-separated state, leading to a quantum yield around 0.46 for formation of the fully chargeseparated state.

The lifetimes of the fully charge-separated states are in the microsecond regime in the ruthenium and iridium triads. Three factors may be responsible for these slow recombination kinetics: (i) inverted driving-force effect, ${ }^{47,67}$ (ii) long electron-hole separation distance $(\sim 22 \AA),{ }^{68-69}$ and (iii) spin selection rule. ${ }^{70}$ In the case of the osmium triad, the lifetime of the fully charge-separated state is more than an order of magnitude shorter than in the ruthenium and iridium systems, possibly because of a relatively small energy gap between the TAA-Os ${ }^{\mathrm{III}}-\mathrm{AQ}^{-}$state and the $\mathrm{TAA}^{+}-\mathrm{Os}^{\mathrm{II}}-\mathrm{AQ}^{-}$state. It thus appears that a large energy gap (here: $>0.45 \mathrm{eV}$ ) to the energetically next higher lying electronic state is another important ingredient for obtaining a long-lived final charge-separated state. We think this is an important new finding; one would have expected much more similar lifetimes for the charge-separated states of the three triads. The fact that we were able to compare a nearly isostructural series of linear donor-sensitizer-acceptor compounds is a significant advantage in this context. 
Future work on these systems will focus on the role of coupling of intramolecular photoinduced electron transfer to bimolecular proton transfer with reduced anthraquinone as a proton-accepting site. Preliminary results from this work have been communicated recently. ${ }^{71}$

\section{EXPERIMENTAL SECTION}

The syntheses of the organic moieties of the rigid rod-like molecular triads and dyads (triarylamine2,2'-bipyridine-anthraquinone unit for the triad; triarylamine-2,2'-bipyridine and 2,2'-bipyridineanthraquinone units for the dyads) were described in detail in the Supporting Information to one of our previous publications. ${ }^{29}$ Reaction of the individual functionalized bpy ligands with $\mathrm{Ru}(\mathrm{bpy})_{2} \mathrm{Cl}_{2}$, $\mathrm{Os}(\mathrm{bpy})_{2} \mathrm{Cl}_{2}$, and $\left[\operatorname{Ir}(2-(p \text {-tolyl }) \text { pyridine })_{2} \mathrm{Cl}\right]_{2}$ precursors occurred following standard protocols. ${ }^{30-32}$ Briefly, a mixture of the starting materials in ethylene glycol was refluxed overnight under $\mathrm{N}_{2}$. After cooling to room temperature water was added, and the aqueous phase was extracted with $\mathrm{CH}_{2} \mathrm{Cl}_{2}$. The organic phase was dried over $\mathrm{MgSO}_{4}$, and the solvent was removed under reduced pressure. Product purification occurred by column chromatography on silica gel using a mixture of acetone/water/aqueous saturated $\mathrm{KNO}_{3}$ solution $(90 / 9 / 1)$ as the eluent. The desired product was precipitated from the aqueous solution (after acetone removal) by addition of saturated aqueous $\mathrm{KPF}_{6}$ solution.

Product characterization data for TAA-Ru ${ }^{\text {II }}-A Q$, TAA-Ru ${ }^{\text {II }}, \mathrm{Ru}^{\mathrm{II}}-\mathrm{AQ}$ (including ligands for the dyads) have been reported previously. ${ }^{57}$ For all other (new) molecules they are as follows:

TAA-Os ${ }^{\mathrm{II}}$. Obtained in $68 \%$ yield $(53 \mathrm{mg})$ from $30 \mathrm{mg}$ of free ligand ${ }^{29}$ and $35 \mathrm{mg}$ of $\mathrm{Os}(\mathrm{bpy})_{2} \mathrm{Cl}_{2} \cdot{ }^{1} \mathrm{H}$ $\operatorname{NMR}\left(300 \mathrm{MHz}, \mathrm{CD}_{2} \mathrm{Cl}_{2}, 25^{\circ} \mathrm{C}\right): \delta[\mathrm{ppm}]=1.79\left(\mathrm{~s}, 3 \mathrm{H}, \mathrm{CH}_{3}\right), 1.90\left(\mathrm{~s}, 3 \mathrm{H}, \mathrm{CH}_{3}\right), 3.73\left(\mathrm{~s}, 6 \mathrm{H}, \mathrm{OCH}_{3}\right)$, $6.76(\mathrm{~m}, 9 \mathrm{H}), 6.95(\mathrm{~s}, 1 \mathrm{H}, \mathrm{xy}), 7.36(\mathrm{~m}, 5 \mathrm{H}), 7.61(\mathrm{~m}, 6 \mathrm{H}), 7.86(\mathrm{~m}, 6 \mathrm{H}), 8.41$ (m, $6 \mathrm{H})$. ES-MS: m/z $=495.66$ (calculated 495.66 for $\mathrm{C}_{52} \mathrm{H}_{45} \mathrm{~N}_{7} \mathrm{O}_{2} \mathrm{Os}^{2+}$ ). Anal. calcd. for $\mathrm{C}_{52} \mathrm{H}_{45} \mathrm{~N}_{7} \mathrm{O}_{2} \mathrm{OsP}_{2} \mathrm{~F}_{12}$ : C 48.79, $\mathrm{H}$ 
3.54, N 7.66. Found: C 48.44, H 3.47, N 7.50. (The abbreviation "xy" in the NMR data stands for aromatic protons of the $p$-xylene units).

Os ${ }^{\mathrm{II}}$-AQ. Obtained in $49 \%$ yield (64 mg) from $50 \mathrm{mg}$ of free ligand ${ }^{29}$ and $61 \mathrm{mg}$ of Os(bpy $)_{2} \mathrm{Cl}_{2} \cdot{ }^{1} \mathrm{H}$ NMR: $\left(300 \mathrm{MHz}, \mathrm{CD}_{3} \mathrm{CN}, 25^{\circ} \mathrm{C}\right): \delta[\mathrm{ppm}]=2.02\left(\mathrm{~s}, 3 \mathrm{H}, \mathrm{CH}_{3}\right), 2.25\left(\mathrm{~s}, 3 \mathrm{H}, \mathrm{CH}_{3}\right), 7.12(\mathrm{~s}, 1 \mathrm{H}, \mathrm{xy})$, $7.22(\mathrm{~s}, 1 \mathrm{H}, \mathrm{xy}), 7.32(\mathrm{~m}, 5 \mathrm{H}), 7.56(\mathrm{~d}, J=1.5 \mathrm{~Hz}, 1 \mathrm{H}), 7.67(\mathrm{~m}, 4 \mathrm{H}), 7.83(\mathrm{~m}, 4 \mathrm{H}), 7.90(\mathrm{~m}, 6 \mathrm{H})$, $8.12(\mathrm{~d}, J=1.6 \mathrm{~Hz}, 1 \mathrm{H}), 8.29(\mathrm{~m}, 3 \mathrm{H}), 8.50(\mathrm{~m}, 6 \mathrm{H}) . \mathrm{ES}-\mathrm{MS} \mathrm{m} / \mathrm{z}=485.133$ (calculated 485.135 for $\mathrm{C}_{52} \mathrm{H}_{38} \mathrm{~N}_{6} \mathrm{O}_{2} \mathrm{Os}^{2+}$ ). Anal. calcd. for $\mathrm{C}_{52} \mathrm{H}_{38} \mathrm{~N}_{6} \mathrm{O}_{2} \mathrm{OsP}_{2} \mathrm{~F}_{12} \cdot 1.5 \mathrm{H}_{2} \mathrm{O}$ : C 48.56, H 3.21, N 6.53. Found C 48.66, H 3.13, N 6.49.

TAA-Os ${ }^{\mathrm{II}}-\mathrm{AQ}$. Obtained in $72 \%$ yield from $30 \mathrm{mg}$ of free ligand ${ }^{29}$ and $21 \mathrm{mg}$ of $\mathrm{Os}(\mathrm{bpy})_{2} \mathrm{Cl}_{2} \cdot{ }^{1} \mathrm{H}$ $\operatorname{NMR}\left(300 \mathrm{MHz}, \mathrm{CD}_{2} \mathrm{Cl}_{2}, 25^{\circ} \mathrm{C}\right): \delta[\mathrm{ppm}]=1.81\left(\mathrm{~s}, 3 \mathrm{H}, \mathrm{CH}_{3}\right), 1.91\left(\mathrm{~s}, 3 \mathrm{H}, \mathrm{CH}_{3}\right), 1.97\left(\mathrm{~s}, 3 \mathrm{H}, \mathrm{CH}_{3}\right)$, $2.34\left(\mathrm{~s}, 3 \mathrm{H}, \mathrm{CH}_{3}\right), 3.74\left(\mathrm{~s}, 6 \mathrm{H}, \mathrm{OCH}_{3}\right), 6.77$ (m, $8 \mathrm{H}$, amine), 6.99 (s, $\left.1 \mathrm{H}\right), 7.14(\mathrm{~s}, 1 \mathrm{H}), 7.16(\mathrm{~s}, 1 \mathrm{H})$, $7.35(\mathrm{~m}, 2 \mathrm{H}), 7.46(\mathrm{~m}, 3 \mathrm{H}), 7.57(\mathrm{~m}, 2 \mathrm{H}), 7.67(\mathrm{~m}, 2 \mathrm{H}), 7.73(\mathrm{~m}, 1 \mathrm{H}), 7.82(\mathrm{~m}, 6 \mathrm{H}), 7.92(\mathrm{~m}, 4 \mathrm{H})$, $8.20(\mathrm{~m}, 1 \mathrm{H}), 8.30(\mathrm{~m}, 3 \mathrm{H}), 8.45(\mathrm{~m}, 4 \mathrm{H}), 8.59(\mathrm{~m}, 2 \mathrm{H})$. ES-MS: m/z = 650.71 (calculated 650.71 for $\mathrm{C}_{74} \mathrm{H}_{59} \mathrm{~N}_{7} \mathrm{O}_{4} \mathrm{Os}^{2+}$ ). Anal. calcd. for $\mathrm{C}_{74} \mathrm{H}_{59} \mathrm{~N}_{7} \mathrm{O}_{4} \mathrm{OsP}_{2} \mathrm{~F}_{12} \cdot 2 \mathrm{H}_{2} \mathrm{O}: \mathrm{C}$ 54.64, H 3.90, N 6.03. Found: C 54.41, H 3.79, N 6.04 .

TAA-Ir ${ }^{\mathrm{III}}$. Obtained in $73 \%$ yield $(28 \mathrm{mg})$ from refluxing $28 \mathrm{mg}$ of organic ligand ${ }^{29}$ with $30 \mathrm{mg}$ of $\left[\operatorname{Ir}(2-(p \text {-tolyl }) \text { pyridine })_{2} \mathrm{Cl}\right]_{2}{ }^{30}$ in a mixture of ethanol $(10 \mathrm{~mL})$ and chloroform $(3 \mathrm{~mL})$. After cooling to room temperature and addition of a saturated aqueous solution of $\mathrm{KPF}_{6}$ a yellow-orange solid formed. This solid was filtered, washed with water and diethylether, and dried under vacuum. ${ }^{1} \mathrm{H}$ NMR (300 $\left.\mathrm{MHz}, \mathrm{CD}_{2} \mathrm{Cl}_{2}, 25^{\circ} \mathrm{C}\right): \delta[\mathrm{ppm}]=1.80\left(\mathrm{~s}, 3 \mathrm{H}, \mathrm{CH}_{3}\right), 1.92\left(\mathrm{~s}, 3 \mathrm{H}, \mathrm{CH}_{3}\right), 2.11\left(\mathrm{~s}, 6 \mathrm{H}, \mathrm{CH}_{3}\right), 3.73(\mathrm{~s}, 6 \mathrm{H}$, $\left.\mathrm{OCH}_{3}\right), 6.08(\mathrm{~s}, 1 \mathrm{H}), 6.15(\mathrm{~s}, 1 \mathrm{H}), 6.78(\mathrm{~m}, 9 \mathrm{H}), 6.93(\mathrm{~m}, 5 \mathrm{H}), 7.43(\mathrm{~m}, 1 \mathrm{H}), 7.56(\mathrm{~m}, 4 \mathrm{H}), 7.74(\mathrm{~m}$, $2 \mathrm{H}), 7.88(\mathrm{~m}, 2 \mathrm{H}), 8.05(\mathrm{~m}, 4 \mathrm{H}), 8.51(\mathrm{~m}, 2 \mathrm{H})$. ES-MS: m/z = 1016.35 (calculated 1016.35 for $\mathrm{C}_{56} \mathrm{H}_{49} \mathrm{~N}_{5} \mathrm{O}_{2} \mathrm{Ir}^{+}$). Anal. calcd. for $\mathrm{C}_{56} \mathrm{H}_{49} \mathrm{~N}_{5} \mathrm{O}_{2} \mathrm{IrPF}_{6} \cdot \mathrm{H}_{2} \mathrm{O}: \mathrm{C}$ 57.04, H 4.36, N 5.94. Found: C 57.10, H 4.22, N 5.87.

Ir $^{\mathrm{III}}$-AQ. Obtained in $80 \%$ yield $(24 \mathrm{mg})$ from $27 \mathrm{mg}$ of organic ligand ${ }^{29}$ and $30 \mathrm{mg}$ of $[\operatorname{Ir}(2-(p-$ tolyl)pyridine $\left.)_{2} \mathrm{Cl}\right]_{2}{ }^{30}$ following the procedure described above for TAA-Ir ${ }^{\mathrm{III}} \cdot{ }^{1} \mathrm{H}$ NMR: $(300 \mathrm{MHz}$, 
$\left.\mathrm{CD}_{3} \mathrm{CN}, 25^{\circ} \mathrm{C}\right): \delta[\mathrm{ppm}]=1.99\left(\mathrm{~s}, 3 \mathrm{H}, \mathrm{CH}_{3}\right), 2.07\left(\mathrm{~s}, 3 \mathrm{H}, \mathrm{CH}_{3}\right), 2.11\left(\mathrm{~s}, 3 \mathrm{H}, \mathrm{CH}_{3}\right), 2.27\left(\mathrm{~s}, 3 \mathrm{H}, \mathrm{CH}_{3}\right)$, $6.12(\mathrm{~s}, 1 \mathrm{H}), 6.17(\mathrm{~s}, 1 \mathrm{H}), 6.88(\mathrm{~m}, 2 \mathrm{H}), 7.01(\mathrm{~m}, 2 \mathrm{H}), 7.16(\mathrm{~s}, 1 \mathrm{H}), 7.23(\mathrm{~s}, 1 \mathrm{H}), 7.52(\mathrm{~m}, 1 \mathrm{H}), 7.63$ (m, $1 \mathrm{H}), 7.69(\mathrm{~m}, 3 \mathrm{H}), 7.83(\mathrm{~m}, 3 \mathrm{H}), 7.90(\mathrm{~m}, 2 \mathrm{H}), 8.00(\mathrm{~m}, 4 \mathrm{H}), 8.17(\mathrm{~m}, 3 \mathrm{H}), 8.29(\mathrm{~m}, 3 \mathrm{H}), 8.57$ (m, $2 \mathrm{H}$ ). ES-MS m/z = 995.29 (calculated 995.29 for $\mathrm{C}_{56} \mathrm{H}_{42} \mathrm{~N}_{4} \mathrm{O}_{2} \mathrm{Ir}^{+}$). Anal. calcd. for $\mathrm{C}_{56} \mathrm{H}_{42} \mathrm{~N}_{4} \mathrm{O}_{2} \mathrm{IrPF}_{6}$ $\cdot 0.3 \mathrm{CHCl}_{3}$ : C 57.50, H 3.63, N 4.76. Found C 57.74, H 3.41, N 4.73.

TAA-Ir ${ }^{\mathrm{III}}-\mathrm{AQ}$. Obtained in $87 \%$ yield $(34 \mathrm{mg})$ from $46 \mathrm{mg}$ of organic ligand ${ }^{29}$ and $30 \mathrm{mg}$ of [ $\operatorname{Ir}(2-(p-$ tolyl)pyridine $\left.)_{2} \mathrm{Cl}\right]_{2}{ }^{30}$ following the procedure described above for TAA-IrII.${ }^{1} \mathrm{H}$ NMR $(300 \mathrm{MHz}$, $\left.\mathrm{CD}_{2} \mathrm{Cl}_{2}, 25^{\circ} \mathrm{C}\right): \delta[\mathrm{ppm}]=1.81\left(\mathrm{~s}, 3 \mathrm{H}, \mathrm{CH}_{3}\right), 1.93\left(\mathrm{~s}, 3 \mathrm{H}, \mathrm{CH}_{3}\right), 1.97\left(\mathrm{~s}, 3 \mathrm{H}, \mathrm{CH}_{3}\right), 2.10\left(\mathrm{~m}, 6 \mathrm{H}, \mathrm{CH}_{3}\right)$, $2.28\left(\mathrm{~s}, 3 \mathrm{H}, \mathrm{CH}_{3}\right), 3.75\left(\mathrm{~s}, 6 \mathrm{H}, \mathrm{OCH}_{3}\right), 6.15(\mathrm{~m}, 2 \mathrm{H}), 6.78\left(\mathrm{~m}, 8 \mathrm{H}, \mathrm{C}_{6} \mathrm{H}_{4}\right), 6.88(\mathrm{~m}, 2 \mathrm{H}), 6.99(\mathrm{~m}, 3$ H), 7.17 (m, 2 H), $7.62(\mathrm{~m}, 4 \mathrm{H}), 7.77(\mathrm{~m}, 3 \mathrm{H}), 7.83(\mathrm{~m}, 2 \mathrm{H}), 7.89$ (m, $2 \mathrm{H}), 8.10(\mathrm{~m}, 2 \mathrm{H}), 8.16$ (m, 2 H), $8.30(\mathrm{~m}, 5 \mathrm{H}), 8.58(\mathrm{~m}, 2 \mathrm{H})$. ES-MS m/z = 1326.45 (calculated 1326.45 for $\mathrm{C}_{78} \mathrm{H}_{63} \mathrm{~N}_{5} \mathrm{O}_{4} \mathrm{Ir}^{+}$). Anal. calcd. for $\mathrm{C}_{78} \mathrm{H}_{63} \mathrm{~N}_{5} \mathrm{O}_{4} \mathrm{IrPF}_{6}$ : C 63.66, H 4.32, N 4.76. Found C 64.00, H 4.45, N 4.78.

${ }^{1}$ H NMR spectroscopy was performed using Bruker Avance DRX 300 and Bruker B-ACS-120 spectrometers. A Finnigan MAT8200 instrument was employed for mass spectrometry, and elemental analysis was performed on a Vario EL III CHNS analyzer from Elementar. Cyclic voltammograms were obtained using a Versastat3-200 potentiostat from Princeton Applied Research. A glassy carbon disk was used as a working electrode. A silver wire served as a quasi-reference electrode and a second silver wire was used as a counter electrode. Voltage sweeps occurred at rates of $100 \mathrm{mV} / \mathrm{s}$, solutions were deoxygenated by bubbling $\mathrm{N}_{2}$ gas prior to measurements. Optical absorption spectra were recorded on a Cary 300 spectrometer from Varian. Spectro-electrochemical experiments were performed using the Cary 300 spectrometer, the potentiostat mentioned above, and an optically transparent thin-layer (OTTLE) cell from Specac. ${ }^{72}$ Steady-state luminescence spectra were measured on a Fluorolog-3 instrument (FL322) from Horiba Jobin-Yvon, equipped with a TBC-07C detector from Hamamatsu. Transient absorption and time-resolved luminescence in the nanosecond time domain was measured using an LP920-KS instrument from Edinburgh Instruments. The detection system of the LP920-KS spectrometer consisted of an R928 photomultiplier and an iCCD camera from Andor. The excitation 
source was a Quantel Brilliant b laser (frequency-doubled or -tripled). Prior to nanosecond time-resolved measurements, samples were thoroughly de-oxygenated by bubbling $\mathrm{N}_{2}$ gas through the solutions, or by using home-built quartz cuvettes and a freeze-pump-thaw technique for oxygen removal. The sample absorbance at the excitation wavelength was typically between 0.1 and 0.3 . A pump-probe method for time-resolved absorption was used to detect fast processes with a time resolution of 150 fs. The femtosecond pulse generator (TISSA50, Avesta/CDP) was pumped with a continuous wave Nd:YAG second harmonic laser (Verdi-V6, Coherent). The femtosecond pulses were amplified with a TiSapphire amplifier (Avesta/CDP) pumped by a Nd:YAG laser (LF114, Solar TII). After the amplifier, the beam was split in two separate beams. The first part was passed through a second harmonic generator to obtain excitation (pump) pulses at $400 \mathrm{~nm}$ or $420 \mathrm{~nm}$, and the second part was passed through a cuvette with water to generate a white light continuum as the monitoring (probe) pulse. The excitation beam was directed to a delay line (Avesta/CDP), enabling measurements of the transient absorption spectra up to $1 \mathrm{~ns}$ after excitation. A monochromator (Andor 0032) and a CCD camera (Newton DU920N-BR-DD, Andor) were used to record the spectra. The sample was placed in a rotating cuvette to prevent any degradation due to the laser excitation. The obtained time-resolved absorption decay curves were globally fitted to a sum of exponentials. The instrumental setup and the data analysis procedure are described in more detail elsewhere. ${ }^{73}$

\section{ACKNOWLEDGMENT}

This work was supported by the Deutsche Forschungsgemeinschaft (DFG) through grants number WE4815/1-1 and INST186/872-1 and by the Academy of Finland.

\section{REFERENCES}


(1) Balzani, V., Electron transfer in chemistry. VCH Wiley: Weinheim, 2001; Vol. 3.

(2) Collin, J.-P.; Guillerez, S.; Sauvage, J.-P.; Barigelletti, F.; De Cola, L.; Flamigni, L.; Balzani, V., Inorg. Chem. 1991, 30, 4230-4238.

(3) Collin, J.-P.; Guillerez, S.; Sauvage, J.-P.; Barigelletti, F.; Flamigni, L.; De Cola, L.; Balzani, V., Coord. Chem. Rev. 1991, 111, 291-296.

(4) Collin, J.-P.; Guillerez, S.; Sauvage, J.-P.; Barigelletti, F.; De Cola, L.; Flamigni, L.; Balzani, V., Inorg. Chem. 1992, 31, 4112-4117.

(5) Sauvage, J.-P.; Collin, J.-P.; Chambron, J.-C.; Guillerez, S.; Coudret, C.; Balzani, V.; Barigelletti, F.; De Cola, L.; Flamigni, L., Chem. Rev. 1994, 94, 993-1019.

(6) Collin, J.-P.; Dixon, I. M.; Sauvage, J.-P.; Williams, J. A. G.; Barigelletti, F.; Flamigni, L., J. Am. Chem. Soc. 1999, 121, 5009-5016.

(7) Dixon, I. M.; Collin, J.-P.; Sauvage, J.-P.; Barigelletti, F.; Flamigni, L., Angew. Chem. Int. Ed. 2000, 39, 1292-1295.

(8) Dixon, I. M.; Collin, J.-P.; Sauvage, J.-P.; Flamigni, L.; Encinas, S.; Barigelletti, F., Chem. Soc. Rev. 2000, 29, 385-391.

(9) Chakraborty, S.; Wadas, T. J.; Hester, H.; Schmehl, R.; Eisenberg, R., Inorg. Chem. 2005, 44, 6865-6878.

(10) Goransson, E.; Boixel, J.; Monnereau, C.; Blart, E.; Pellegrin, Y.; Becker, H. C.; Hammarström, L.; Odobel, F., Inorg. Chem. 2010, 49, 9823-9832.

(11) Roundhill, D. M., Photochemistry and Photophysics of Metal Complexes. Plenum Press: New York, 1994.

(12) Baranoff, E.; Collin, J.-P.; Flamigni, L.; Sauvage, J.-P., Chem. Soc. Rev. 2004, 33, 147-155. 
(13) Flamigni, L.; Collin, J.-P.; Sauvage, J.-P., Acc. Chem. Res. 2008, 41, 857-871.

(14) Abrahamsson, M.; Jager, M.; Osterman, T.; Eriksson, L.; Persson, P.; Becker, H. C.; Johansson, O.; Hammarström, L., J. Am. Chem. Soc. 2006, 128, 12616-12617.

(15) Abrahamsson, M.; Jager, M.; Kumar, R. J.; Osterman, T.; Persson, P.; Becker, H. C.; Johansson, O.; Hammarström, L., J. Am. Chem. Soc. 2008, 130, 15533-15542.

(16) Hammarström, L.; Johansson, O., Coord. Chem. Rev. 2010, 254, 2546-2559.

(17) Kumar, R. J.; Karlsson, S.; Streich, D.; Jensen, A. R.; Jager, M.; Becker, H. C.; Bergquist, J.; Johansson, O.; Hammarström, L., Chem.-Eur. J. 2010, 16, 2830-2842.

(18) Cooley, L. F.; Larson, S. L.; Elliott, C. M.; Kelley, D. F., J. Phys. Chem. 1991, 95, 10694-10700.

(19) Opperman, K. A.; Mecklenburg, S. L.; Meyer, T. J., Inorg. Chem. 1994, 33, 5295-5301.

(20) Larson, S. L.; Elliott, C. M.; Kelley, D. F., J. Phys. Chem. 1995, 99, 6530-6539.

(21) Treadway, J. A.; Chen, P. Y.; Rutherford, T. J.; Keene, F. R.; Meyer, T. J., J. Phys. Chem. A 1997, 101, 6824-6826.

(22) Rutherford, T. J.; Keene, F. R., Inorg. Chem. 1997, 36, 2872-2878.

(23) Klumpp, T.; Linsenmann, M.; Larson, S. L.; Limoges, B. R.; Bürssner, D.; Krissinel, E. B.; Elliott, C. M.; Steiner, U. E., J. Am. Chem. Soc. 1999, 121, 1076-1087.

(24) Maxwell, K. A.; Sykora, M.; DeSimone, J. M.; Meyer, T. J., Inorg. Chem. 2000, 39, 71-75.

(25) Borgström, M.; Johansson, O.; Lomoth, R.; Baudin, H. B.; Wallin, S.; Sun, L. C.; Åkermark, B.; Hammarström, L., Inorg. Chem. 2003, 42, 5173-5184.

(26) Falkenström, M.; Johansson, O.; Hammarström, L., Inorg. Chim. Acta 2007, 360, 741-750.

(27) Wenger, O. S., Coord. Chem. Rev. 2009, 253, 1439-1457. 
(28) Dupont, N.; Ran, Y. F.; Jia, H. P.; Grilj, J.; Ding, J.; Liu, S. X.; Decurtins, S.; Hauser, A., Inorg. Chem. 2011, 50, 3295-3303.

(29) Hankache, J.; Wenger, O. S., Chem. Commun. 2011, 47, 10145-10147.

(30) Freys, J. C.; Bernardinelli, G.; Wenger, O. S., Chem. Commun. 2008, 4267-4269.

(31) Hanss, D.; Freys, J. C.; Bernardinelli, G.; Wenger, O. S., Eur. J. Inorg. Chem. 2009, 4850-4859.

(32) Sullivan, B. P.; Salmon, D. J.; Meyer, T. J., Inorg. Chem. 1978, 17, 3334-3341.

(33) Hanss, D.; Wenger, O. S., Inorg. Chem. 2008, 47, 9081-9084.

(34) Hanss, D.; Wenger, O. S., Eur. J. Inorg. Chem. 2009, 3778-3790.

(35) Geiss, B.; Lambert, C., Chem. Commun. 2009, 1670-1672.

(36) Sreenath, K.; Suneesh, C. V.; Gopidas, K. R.; Flowers, R. A., J. Phys. Chem. A 2009, 113, $6477-$ 6483.

(37) Meyer, T. J., Pure Appl. Chem. 1986, 58, 1193-1206.

(38) Balzani, V.; Juris, A.; Venturi, M.; Campagna, S.; Serroni, S., Chem. Rev. 1996, 96, 759-833.

(39) Juris, A.; Balzani, V.; Barigelletti, F.; Campagna, S.; Belser, P.; Von Zelewsky, A., Coord. Chem. Rev. 1988, 84, 85-277.

(40) Lamansky, S.; Djurovich, P.; Murphy, D.; Abdel-Razzaq, F.; Kwong, R.; Tsyba, I.; Bortz, M.; Mui, B.; Bau, R.; Thompson, M. E., Inorg. Chem. 2001, 40, 1704-1711.

(41) McCusker, J. K., Acc. Chem. Res. 2003, 36, 876-887.

(42) Lowry, M. S.; Bernhard, S., Chem. Eur. J. 2006, 12, 7970-7977. 
(43) Baranoff, E.; Dixon, I. M.; Collin, J.-P.; Sauvage, J.-P.; Ventura, B.; Flamigni, L., Inorg. Chem. 2004, 43, 3057-3066.

(44) The absorbance at the excitation wavelength was typically in the range between 0.1 and 0.3 . The individual luminescence intensities were corrected for differences in absorbance at the excitation wavelength.

(45) Turro, N. J., Molecular Photochemistry. New York, Amsterdam, 1967.

(46) Marsal, P.; Avilov, I.; da Silva, D. A.; Bredas, J. L.; Beljonne, D., Chem. Phys. Lett. 2004, 392, $521-528$.

(47) Schanze, K. S.; MacQueen, D. B.; Perkins, T. A.; Cabana, L. A., Coord. Chem. Rev. 1993, 122, 63-89.

(48) Schoonover, J. R.; Dattelbaum, D. M.; Malko, A.; Klimov, V. I.; Meyer, T. J.; Styers-Barnett, D. J.; Gannon, E. Z.; Granger, J. C.; Aldridge, W. S.; Papanikolas, J. M., J. Phys. Chem. A 2005, 109, $2472-2475$.

(49) Simon, J. A.; Curry, S. L.; Schmehl, R. H.; Schatz, T. R.; Piotrowiak, P.; Jin, X. Q.; Thummel, R. P., J. Am. Chem. Soc. 1997, 119, 11012-11022.

(50) Freys, J. C.; Wenger, O. S., Eur. J. Inorg. Chem. 2010, 5509-5516.

(51) Creutz, C.; Chou, M.; Netzel, T. L.; Okumura, M.; Sutin, N., J. Am. Chem. Soc. 1980, 102, 1309-1319.

(52) Walther, M. E.; Wenger, O. S., Inorg. Chem. 2011, 50, 10901-10907.

(53) Furue, M.; Maruyama, K.; Oguni, T.; Naiki, M.; Kamachi, M., Inorg. Chem. 1992, 31, $3792-$ 3795. 
(54) Anderson, P. A.; Keene, F. R.; Meyer, T. J.; Moss, J. A.; Strouse, G. F.; Treadway, J. A., J. Chem. Soc., Dalton Trans. 2002, 3820-3831.

(55) Sreenath, K.; Thomas, T. G.; Gopidas, K. R., Org. Lett. 2011, 13, 1134-1137.

(56) Babaei, A.; Connor, P. A.; McQuillan, A. J.; Umapathy, S., J. Chem. Ed. 1997, 74, 1200-1204.

(57) Hankache, J.; Wenger, O. S., Phys. Chem. Chem. Phys. 2012, 14, 2685-2692.

(58) Weller, A., Z. Phys. Chem. 1982, 133, 93-98.

(59) Lambert, C.; Nöll, G., J. Am. Chem. Soc. 1999, 121, 8434-8442.

(60) Hankache, J.; Wenger, O. S., Chem. Rev. 2011, 111, 5138-5178.

(61) Lewis, F. D.; Thazhathveetil, A. K.; Zeidan, T. A.; Vura-Weis, J.; Wasielewski, M. R., J. Am. Chem. Soc. 2010, 132, 444-445.

(62) Mecklenburg, S. L.; McCafferty, D. G.; Schoonover, J. R.; Peek, B. M.; Erickson, B. W.; Meyer, T. J., Inorg. Chem. 1994, 33, 2974-2983.

(63) The shorter lifetime of the fully charge-separated state in the osmium triad explains the lower signal-to-noise ratio in the transient absorption spectrum of Figure $4 \mathrm{~b}$ relative to those of Figure $4 \mathrm{a} / \mathrm{c}$.

(64) Lancaster, K.; Odom, S. A.; Jones, S. C.; Thayumanavan, S.; Marder, S. R.; Brédas, J. L.; Coropceanu, V.; Barlow, S., J. Am. Chem. Soc. 2009, 131, 1717-1723.

(65) Nelsen, S. F.; Konradsson, A. E.; Weaver, M. N.; Telo, J. P., J. Am. Chem. Soc. 2003, 125, 12493-12501.

(66) Nelsen, S. F.; Weaver, M. N.; Zink, J. I.; Telo, J. P., J. Am. Chem. Soc. 2005, 127, 10611-10622.

(67) Marcus, R. A.; Sutin, N., Biochim. Biophys. Acta 1985, 811, 265-322.

(68) Gray, H. B.; Winkler, J. R., Proc. Natl. Acad. Sci. U. S. A. 2005, 102, 3534-3539. 
(69) Wenger, O. S., Acc. Chem. Res. 2011, 25-35.

(70) Weiss, E. A.; Ahrens, M. J.; Sinks, L. E.; Ratner, M. A.; Wasielewski, M. R., J. Am. Chem. Soc. 2004, 126, 9510-9511.

(71) Hankache, J.; Wenger, O. S., Chem. Eur. J. 2012, DOI: 10.1002/chem.201200199.

(72) Krejčik, M.; Daněk, M.; Hartl, F., J. Electroanal. Chem. 1991, 317, 179-187.

(73) Tkachenko, N. V.; Rantala, L.; Tauber, A. Y.; Helaja, J.; Hynninen, P. H.; Lemmetyinen, H., J. Am. Chem. Soc. 1999, 121, 9378-9387.

\section{SYNOPSIS TOC}

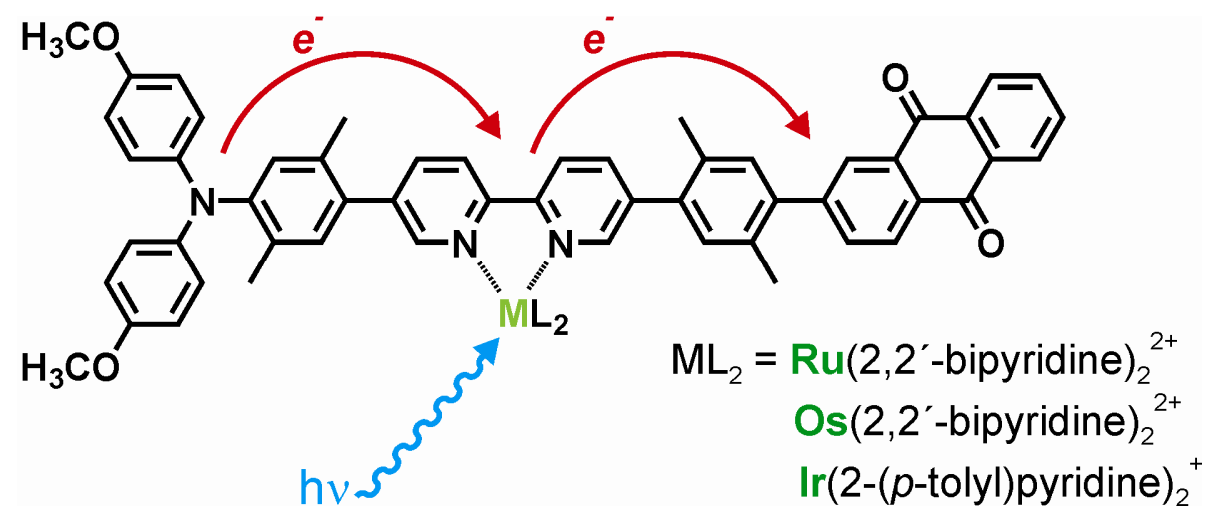

Despite great chemical similarities between the $\mathrm{Ru}(\mathrm{II})$, Os(II), and $\mathrm{Ir}(\mathrm{III})$ based electron transfer triads investigated in this work, there are significant differences in photophysical and photochemical properties between them. Among these differences are variations in electron transfer pathways and kinetics, as well as significant differences in the quantum yields with which fully charge-separated states are formed. The lifetimes of these energy-storing charge-separated states vary over a rather wide range from $80 \mathrm{~ns}$ to $1300 \mathrm{~ns}$. 